\title{
Contributo ad una rilettura dello statto di necessità
}

\author{
Contribuição a uma releitura do estado de necessidade
}

\section{Contribution to a re-reading of the state of necessity}

\section{Luigi Nonne ${ }^{* *}$}

\begin{abstract}
L'art. 2045 c.c., regolando lo stato di necessità con riferimento all'illecito extracontrattuale, individua i requisiti della causa di giustificazione nel pericolo (attuale, non volontariamente provocato, inevitabile), nella situazione soggettiva del danneggiante (l'intento di salvaguardare un diritto della persona proprio o di altri da una lesione grave) e nel danno cagionato ad un terzo incolpevole. L'analisi dei profili che la norma esige perché l'obbligo di risarcimento sia sostituito dalla corresponsione di un'indennità consente di evidenziare alcuni aspetti che la previsione codicistica dello stato di necessità lascia ancora irrisolti. In particolare, il saggio si concentra sul pericolo cagionato dal fatto illecito del terzo, sul soccorso di necessità e sulla possibile applicazione dell'art. 2045 c.c. alle ipotesi in cui il debitore è costretto a non eseguire la prestazione dovuta al creditore in virtù di una situazione necessitante. Scopo della ricerca, allora, è quello di individuare il ruolo assunto dallo stato di necessità nella disciplina dell'illecito civile, contrattuale ed extracontrattuale.
\end{abstract}

Parole Chiave: Stato di necessità. Danno. Disciplina dell'illecito civile.

\section{Resumo}

O artigo 2045 do Código Civil italiano, regulando o estado de necessidade, com referência ao ilícito extracontratual, identifica os requisitos da causa justificadora no perigo (atual, não intencionalmente provocado, inevitável), na situação subjetiva do causador do dano (a intenção de proteger o direito da própria pessoa ou de outros de uma lesão grave) e no dano causado a um terceiro inocente. A análise dos perfis que a lei exige para a obrigação de ressarcimento para ser substituída pelo pagamento de uma indenização permite destacar alguns aspectos que a previsão codicista do estado de necessidade ainda não resolveu. Em particular, o artigo centra-se no perigo causado pelo ato ilícito do terceiro, no resgate das necessidades e na possível aplicação do art. 2045 do Código Civil italiano para as hipóteses em que o devedor é obrigado a não realizar o serviço devido ao credor em virtude de uma situação em necessidade. O objetivo da pesquisa é, então, identificar o papel assumido pelo estado de necessidade na disciplina de delito civil, contratual e extracontratual.

Palavras-chave: Estado de necessidade. Dano. Disciplina do ilícito civil.

\section{Abstract}

Article 2045 of the Italian Civil Code, regulating the state of necessity, with reference to the non-contractual offense, identifies the requirements of the justifying cause in the danger (current, unintentionally provoked, unavoidable), the subjective situation of the person causing the harm (the intention to protect the right of the person or others to a serious injury) and harm caused to an innocent third party. The analysis of the profiles that the law requires for the obligation of compensation to be replaced by the payment of indemnity allows highlighting some aspects that the code prediction of the state of necessity has not yet solved. In particular, the article focuses on the danger caused by the illicit act of the third party, in the rescue of the needs and in the possible application of article 2045 of the Italian Civil Code for cases

II presente lavoro costituisce lo sviluppo della Relazione presentata al Convegno "La dottrina di Salvatore Piras a trent'anni dalla scomparsa", organizzato dal Dipartimento di Giurisprudenza dell'Università degli studi di Sassari e tenutosi a Sassari il giorno 13 novembre 2015 . In particolare, si è tratto spunto dal "Saggio sul comportamento necessitato nel diritto privato" del Prof. Salvatore Piras, apparso prima come lavoro monografico, pubblicato, nel 1948, dall'editore Gallizzi di Sassari (pp. 7-109, dal quale si citerà), e, nell'anno successivo, come articolo negli Studi Sassaresi (1949, serie II, vol. XII, fascicolo III-IV, pp. 117-201). Alcuni tra i risultati raggiunti nella relativa indagine sono oggetto del saggio Profili critici dello stato di necessità nel diritto privato, in corso di pubblicazione nella Rivista di diritto civile.

" Dottore ri ricerca presso l'Università degli Studi di Sassari - Italia. Professore Associato di Diritto Privato nell'Università degli Studi di Sassari Italia. Sassari - Italia. E-mail: Inonne@uniss.it. 
where the debtor is obliged not to perform the service due to the creditor because of a situation in need. The objective of the research is then to identify the role assumed by the state of necessity in the discipline of civil, contractual and extra-contractual crime.

Keywords: State of necessity. Damage. Discipline of civil unlawful.

\section{Introduzione}

Una rilettura dello stato di necessità nel diritto privato ${ }^{1}$ aspira a ricomporre il ruolo sistematico dell'istituto nella disciplina della responsabilità extracontrattuale, là dove è collocato l'art. 2045 c.c. ${ }^{2}$ oltre a verificarne l'ipotetico àmbito di applicazione in quella contrattuale.

Dalla relativa trattazione, cui saranno dedicate queste riflessioni, sarà esclusa la necessità come presupposto del rimedio rescissorio nel contratto concluso in stato di pericolo ai sensi dell'art. 1447 c.c. ${ }^{3}$ in relazione al quale è sufficiente constatare in questa sede che l'indennità prevista dalla norma come obbligo eventuale in capo a chi agisce per la rescissione, a differenza di quanto previsto dall'art. 2045 c.c., in cui la medesima mira a compensare il danneggiato incolpevole della lesione subita, è invece stabilita a favore di chi intendeva sfruttare a proprio vantaggio le circostanze nelle quali il contratto fu concluso, nei termini di un equo compenso per l'opera prestata. ${ }^{4}$

Merita sottolineare anzitutto come l'esame della materia abbia ricavato molteplici suggestioni dal profilo comparatistico. ${ }^{5}$ Con riferimento al B.G.B. tedesco, esso disciplina lo stato di necessità, ${ }^{6}$ in termini generali, nel $\S 228$ e, con precipuo riguardo alla proprietà, nel $\S 904,{ }^{7}$ mentre l'A.B.G.B. austriaco riserva alla fattispecie il $\S 1306$ a. ${ }^{8}$ Quanto, invece, al diritto francese, l'istituto, ora presente nel nuovo codice penale del 1992 (entrato in vigore il $1^{\circ}$ marzo 1994) all'art. 122-7, nell'àmbito civilistico, pur in assenza di una disposizione che espressamente ne identifichi il rilievo per il diritto privato, ${ }^{9}$ è stato ricostruito come regola operazionale dalla dottrina, che innesta le proprie argomentazioni su molteplici pronunce giurisprudenziali. ${ }^{10}$ Gli ordinamenti di Common Law attribuiscono anch'essi alla Defense of Private Necessity

Si avverte che, quando saranno affrontati argomenti collaterali molto frequentati nella letteratura e nella giurisprudenza, i rinvii alle fonti, pur ritenuti essenziali, sono esemplificativi.

2 L'evoluzione storica dello stato di necessità conferma il precipuo rilievo delle relative fattispecie nell'àmbito del fatto illecito delittuale; cfr. sul punto F. Japoce (1917, p. 15-37), con riferimento all'elaborazione dell'istituto nel diritto romano e intermedio (per il diritto romano e comune si veda anche J. Hogenschurz (1997, p. 18-22, e § 2 B I-II, p. 23-27).

3 C. M. Bianca (2012, p. 664) qualifica a questo proposito lo stato di necessità come causa di invalidità del contratto, mentre nel tema dell'illecito esso si caratterizza nel senso di un'esimente della responsabilità.

4 Cfr. sul punto S. Rossi (2012, p. 704-721, alle p. 705 s.), il quale precisa che nella fattispecie ex art. 1447 c.c. "lo stato di pericolo è vassallo dell'iniquità contrattuale, essendo essenzialmente volto a fornire un rimedio allo squilibrio del sinallagma contrattuale" (p. 706).

5 L'argomento è stato affrontato in questa prospettiva già nella breve sintesi di F. Japoce (1917, p. 37-43). Cfr. per una visione d'insieme J. Limpens - R. M. Kruithof - A. Meinertzhagen-Limpens (1983, Part 1, Chapt. 2, par. VI., 2-165 - 2-192, p. 81-93, spec. 2-170 - 2-180, p. 83-87).

6 Si veda H. Stoll (1987, p. 210-213) e, nei commentarî più autorevoli, H. Grothe (2006, p. 2534-2541), e F. J. Säcker (2004, p. 636-642); J. Ellenberger (2015 p. 252-253), e P. Bassenge (2015, p. 1532-1533); O. Werner (2001, p. 786-796), e H. H. Seiler (2002, p. 61-85). Può utilmente consultarsi, benché risalente, anche O. Gericke (1909, p. 26-45).

Cfr. a titolo esemplificativo J. Hogenschurz (1997, p. 36-144), sul fondamento della responsabilità nello stato di necessità e sulla imputazione della medesima, con particolare riguardo all'ipotesi del soccorso necessitato e del soggetto obbligato al risarcimento.

8 Un'indagine di notevole approfondimento dell'istituto nella prospettiva del dialogo tra sistema italiano e (principalmente) ordinamenti di lingua tedesca (o da essi influenzati) è stata compiuta da A. Diurni (2003, p. 13-18) per le coordinate generali del confronto tra gli ordinamenti citati (cfr. anche Id, 1998, specie p. 156-176, con specifico riguardo alle differenze tra regole tedesche e italiane circa il rimedio riparatorio del danno necessitato). Per il diritto svizzero, che prevede lo stato di necessità all'art. $701 \mathrm{ZGB}$ e all'art. $52,2^{\circ}$ e $3^{\circ}$ co., OR, si vedano la Dissertation di H. Trüeb (1924, spec. $\S \S 12-13$, p. 51-75), e quella di V. Landmann (1975) e A. Gambaro-R. Sacco (2008, p. 368), inserisce invece lo stato di necessità all'interno delle disposizioni generali relative all'esercizio e alla tutela dei diritti, prevedendo, all'art. 339. , che debba considerarsi lecita l'azione da cui derivi la distruzione o un danno ai beni altrui, se detta azione sia stata compiuta al fine di respingere il pericolo attuale di un danno manifestamente superiore incombente sull'agente o su un terzo; cfr. sul punto M. J. De Almeida Costa (2009, p. 572-576); P. De Lima - A. Varela (2010, p. 303); P. P. de Vasconcelos (2010, p. 295-296); M. d. G. Trigo (2014, p. 801-805).

9 Peraltro, l'Avant Projet de loi sulla riforma della responsabilità civile, sottoposto a consultazione il 29 aprile 2016 , prevede l'inserimento nel Code civil di un nuovo art. 1257, il cui secondo alinea contempla tra le causes d'exclusion de responsabilité il fait dommageable commandé par la nécessité de la sauvegarde d'un intérêt supérieur (l'Avant Projet è reperibile all'indirizzo http://www.textes.justice.gouv.fr/art_pix/avpjlresponsabilite-civile.pdf).

10 Un quadro molto chiaro del problema in Francia si rinviene in G. Viney - P. Jourdain - S. Carval (2013, p. 663-671 (§§ 566-571). Si vedano inoltre le ancora attuali riflessioni di P. Lallement (1922, spec. §§ 70-114 (p. 79-150), di R. Savatier (1939, p. 729-752), nonché di R. Pallard (1950) e di A. Pirovano (1966, spec. §§ 234-255, p. 210-228). 
un ruolo giustificativo, ${ }^{11}$ pur se il problema della conseguente compensation è oggetto di articolate indagini (SUSSMANN, 1967, p. 184-194).

Lo stato di necessità costituisce una fattispecie complessa, in quanto risulta dalla sintesi delle due subfattispecie o fatti giuridici presupposti dall'art. 2045 c.c.: la situazione necessitante e il comportamento necessitato (COMPORTI, 2002, p. 21-50), i quali sono a loro volta scomponibili in elementi cui è necessario dedicare una specifica trattazione.

\section{La situazione necessitante}

Con riguardo alla situazione necessitante, le posizioni giuridiche attinenti alla persona (PERLINGIERI, 2006, p. 433-436) muovono dal riferimento all'art. 2 Cost., quindi ai diritti inviolabili dell'uomo, ${ }^{12}$ sia come singolo sia nelle formazioni sociali in cui si svolge la relativa personalità (TROISI, 1984, p. 9-13; VENCHIARUTTI, 1988, p. 485). Peraltro, tale tassonomia (ristretta, in quanto per l'appunto riferita a diritti inviolabili) è suscettibile di integrazione,$^{13}$ sì che è pacifica la tutela mediante stato di necessità anche, ad esempio, della paternità morale di un'opera dell'ingegno. ${ }^{14}$

Non sempre, comunque, i diritti di credito possono essere esclusi dal novero degli interessi tutelabili mediante un comportamento necessitato e, perciò, rilevanti ai fini dell'applicazione dell'art. 2045 c.c. (PIRAS, 1948, p. 19). Difatti, qualora il diritto di credito sia strumentale, secondo la sua configurazione normativa, alla diretta soddisfazione di bisogni che attengono alla persona umana, le tipologie di pericolo attuale di un danno grave alla persona dovrebbero arricchirsi anche del temuto pregiudizio a siffatte situazioni patrimoniali, come dimostra esemplarmente la vicenda degli obblighi alimentari ex artt. 433 448-bis c.c. Esemplificando, allora, risulterebbe compiuta in stato di necessità la condotta posta in essere da chi, impedendo a taluno di esercitare la propria libertà di movimento, in tal modo vuole costringere ad adempiere l'obbligo alimentare il soggetto a ciò tenuto per legge ma inadempiente, oppure obbligato all'adempimento entro un termine non ancora scaduto, qualora l'ulteriore attesa comportasse la privazione di beni essenziali per la vita strettamente correlati agli alimenti, come il vitto, l'alloggio, il vestiario. II profitto nel caso di specie non sarebbe ingiusto, in quanto dovuto dal "sequestrato", né vi sarebbe la possibilità di ricorrere al giudice, visti i tempi di emanazione dei relativi provvedimenti, incompatibili con l'incombenza del pericolo. La fattispecie, pertanto, sarebbe riconducibile non alla previsione penale in materia di sequestro di persona a scopo di estorsione (art. 630 c.p.) o di esercizio arbitrario delle proprie ragioni mediante violenza sulle persone (art. 393 c.p.), bensì alla violenza privata ex art. 610 c.p. Tenuto conto del fatto che, come si vedrà, tra i parametri che il giudice deve utilizzare per la determinazione dell'indennità ai sensi dell'art. 2045 c.c. vi è la condizione economica delle parti (in applicazione analogica dell'art. $2047,2^{\circ}$ co., c.c.), a un simile fatto, penalmente giustificato ma civilmente presupposto della compensazione indennitaria, nella maggior parte delle ipotesi concrete non corrisponderà verosimilmente quest'ultima, benché in astratto dovuta, proprio per le particolari circostanze nelle quali il danno è stato cagionato. Nell'esempio proposto, inoltre, la stessa natura del diritto violato (libertà personale) rende assai difficoltosa la quantificazione patrimoniale

\footnotetext{
Per il diritto inglese cfr. l'agile quadro di J. A. Jolowicz ( 2000, p. 227-232).

2 Per i profili riparatorî che ineriscono alla relativa lesione cfr. E. Navarretta (1996); M. Comporti (1964, p. 44-45), con riferimento alla necessità di salvare animali importanti o cose di particolare valore (come un cavallo o un'opera d'arte), sembra auspicare un ampliamento dell'àmbito applicativo dell'art. 2045 c.c., attesa la grande significatività dei suddetti beni. Si veda, peraltro, Corte cost., ord. n. 130 del 28 marzo 2006 , in Giur. cost., 2006, p. 1221-1224, la quale ha dichiarato manifestamente infondata la questione di costituzionalità dell'art. 2045 c.c., nella parte in cui non prevede un indennizzo anche nell'ipotesi in cui il danneggiante, nel porre in essere una condotta non riprovevole, sia stato mosso dalla salvaguardia di un essere animato non umano o di un interesse di rango meno elevato rispetto a quelli inerenti alla persona.

13 Come considera S. Piras (1948, p. 19), quando parla di interpretazione estensiva dell'art. 2045 c.c.; non distingue tra diritti inviolabili e altri diritti, per i quali la tutela si ricava per l'appunto in base ad un'estensione del significato precettivo della norma in commento; M. Briguglio (1963, p. 23), il quale discorre di interpretazione dichiarativa della locuzione "danno grave alla persona". Secondo G. Fiandaca-E. Musco (2014, p. 320-321), l'interpretazione del concetto di danno alla persona deve evitare restrizioni aprioristiche, in quanto esso è idoneo a ricomprendere qualsiasi lesione minacciata ad un bene personale giuridicamente rilevante in àmbito sia penale sia extrapenale.

14 Sulla scia di S. Piras (1948, p. 18 e 21), si pongono anche M. Briguglio (1963, p. 23, 25-26); B. Troisi (1984, p. 12; M. Franzoni (2010, p. 1148). Sulla peculiare configurazione del rapporto tra il diritto morale di autore e le altre situazioni attinenti alla personalità rinvio a quanto esposto infra, al paragrafo 4 , testo e nota 85 , con riguardo alla supposta integrazione della fattispecie di cui all'art. 2045 c.c. mediante il requisito della proporzionalità tra fatto e pericolo.
} 
del pregiudizio subìto come base per la prestazione compensativa cui sarebbe tenuto il danneggiante..$^{15}$ Qualora, peraltro, tale obbligazione dovesse costituirsi ad opera del giudice, dalle riflessioni precedenti consegue che il relativo diritto non potrà essere opposto in compensazione al necessitato per evitare di adempiere all'obbligazione alimentare (se la relativa prestazione non fosse stata comunque eseguita in séguito alla costrizione), poiché, seppure il danno subito in virtù della condotta giustificata concerne un diritto anch'esso attinente alla sfera della persona(lità), l'indennità ne patrimonializza il ristoro e, rispetto ad essa, prevale la finalità di sostentamento vitale, cui l'art. $447,2^{\circ}$ co., c.c. riconduce il divieto di compensazione a carico dell'obbligato agli alimenti.

Prima di esaminare le qualificazioni che la norma esige per la rilevanza del pericolo, inteso come "probabilità del verificarsi di un pregiudizio o di una lesione dell'interesse tutelato dalla norma con l'attribuzione della titolarità di un diritto soggettivo in capo al relativo soggetto" (PIRAS, 1948, p. 23), merita evidenziare come, seppure è vero che l'origine, o la causa determinante, del pericolo non riveste alcun interesse ai fini dell'integrazione della fattispecie, ${ }^{16}$ la considerazione del suddetto pericolo possa comunque costituire una circostanza di cui il giudice tiene conto nel determinare l'indennità prevista dall'art. 2045 c.c., rimessa espressamente al suo equo apprezzamento. A questo proposito, anche se la questione verrà approfondita in séguito, è opportuno fin d'ora sottolineare che, qualora il pericolo venga posto in essere per il fatto doloso o colposo di un terzo c.d. necessitante, l'indennità dovrebbe essere addirittura esclusa dal giudice. In effetti, poiché la norma mira a riequilibrare, per ragioni di giustizia distributiva (SAVATIER, 1939, p. 730), ${ }^{17}$ la posizione di un soggetto che, essendo stato danneggiato da un atto non illecito, ${ }^{18}$ rimane privo della possibilità di richiedere l'integrale risarcimento del pregiudizio subìto ai sensi dell'art. 2043 c.c., là dove, invece, questa possibilità vi fosse, in quanto il terzo necessitante è responsabile proprio in virtù del citato art. 2043 c.c., un'obbligazione ex art. 2045 c.c. sarebbe inconferente con tale scopo e ben potrebbe il giudice negarne l'insorgere in capo al soggetto necessitato. ${ }^{19}$ In base a ciò, può legittimamente concludersi che la fattispecie in discorso non comporta necessariamente un effetto costitutivo dell'obbligo indennitario (PIRAS, 1948, p. 66-69), ${ }^{20}$ il quale, pertanto, sarà solo eventuale..$^{21}$

Venendo, ora, ai profili del pericolo, esso deve essere grave, ${ }^{22}$ ossia "deve riscontrarsi una notevole e particolare intensità del pregiudizio incombente su quegli interessi primarî che sono tutelati attraverso i diritti" della persona(lità) (PIRAS, 1948, p. 25);23 attuale, "nel senso che tra il momento della previsione del danno ed il suo verificarsi deve intercorrere un intervallo di tempo tale da valere a determinare una immediatezza del danno temuto e a far ritenere fondatamente che non vi sia la possibilità materiale di

15 Cfr. recentemente sul punto A. G. Cianci (2016, p. 210-211), ove si pone peraltro in rilievo il ruolo di primaria importanza assunto nella materia dalla valutazione equitativa del giudice ai sensi dell'art. 1226 c.c. (richiamato in materia extracontrattuale dall'art. 2056 c.c.), atteso che la grande diversità tra le varie ipotesi di lesione della libertà personale rende irrealistico proporre criterî di liquidazione uniformi.

16 Ciò trova conferma nel dato comparatistico; si veda G. Viney - P. Jourdain - S. Carval $(2013$, p. 665).

17 Si veda, inoltre, C. Caricato (2012, p. 52 e 59), dove si precisa che la funzione dell'indennità si ispira "alla concreta esigenza di ripartire tra i soggetti coinvolti le conseguenze economiche del fatto dannoso, e ciò secondo criteri precisi, che portano a certi risultati, i quali vengono poi corretti con l'impiego dell'equità" (enfasi nel testo).

$1^{8}$ Sulle diverse ricostruzioni in merito alla natura giuridica dello stato di necessità rinvio al mio lavoro Profili critici dello stato di necessità nel diritto privato, 2017, par. 3

19 Come si è verificato nella sentenza App. Cagliari, 30 giugno 1961, in Giur. it., 1962, II, cc. 354-360, con nota di B. Cormìo (1961), ove viene esplicitato che, nel caso di specie, "[...] può anche venir meno l'obbligo dell'agente necessitato di corrispondere al danneggiato l'equa indennità, poiché non è certo sufficiente la sussistenza del danno, di per se stessa, a far affermare quell'obbligo" (c. 360).

20 Una diversa ricostruzione è proposta da B. Troisi (1984, p. 33-34), il quale compie un'esegesi dell'art. 2045 c.c., che qualifica l'indennità come dovuta, in coordinata lettura con gli artt. 1447 c.c. e $2047,2^{\circ}$ co., c.c., ove si prevede invece la mera possibilità che essa venga corrisposta, ricavandone che il sorgere dell'obbligazione indennitaria costituisca un effetto essenziale della prima fattispecie. La responsabilità del terzo necessitante, invece, dimostra come la stessa ratio redistributiva dell'art. 2045 c.c. escluda la propria operatività in presenza di un soggetto civilmente responsabile per l'intero ammontare del pregiudizio subito.

21 Seppure l'indennità non fosse riconosciuta per il ricorrere della suddetta circostanza, il relativo valore dovrebbe comunque determinarsi ad opera del giudice, che volesse fare applicazione analogica dell'art. $2047,2^{\circ}$ co., c.c., qualora l'obbligazione del necessitato divenisse efficace (o, rectius, si costituisse) in virtù della mancata integrale soddisfazione del danneggiato ad opera del terzo necessitante. Sul punto vedi infra, par. 3.

22 Di particolare interesse quanto osserva sul punto M. Pogliani (1969, p. 85), il quale, in merito alla gravità del pericolo, sottolinea come non si possa prescindere dall'atteggiamento della volontà dell'agente nel momento in cui si verifica il fatto necessitato, atteggiamento che, essendo condizionato dall'immediatezza della decisione da prendere, determina in una molteplicità di casi la notevole attenuazione dello spirito critico e della facoltà di scelta.

23 R. Scognamiglio (1968, p. 655) osserva che la notevole entità del pregiudizio richiesta dalla norma deve essere vagliata dal punto di vista soggettivo e secondo gli elementi offerti dal comune senso giuridico. La gravità del danno può essere determinata considerando l'eventuale rango del bene minacciato (criterio qualitativo; ad es. il bene vita), oppure tenendo conto del grado di pericolo che incombe sul bene (criterio quantitativo, per cui, in ipotesi, non ogni danno all'integrità fisica può dirsi grave, ma soltanto quello che produce una lesione di particolare rilevanza); in questi termini si veda G. Fiandaca-E. Musco (2014, p. 321). 
riuscire a sfuggire ad esso"; 24 inevitabile, "cioè deve presentarsi in modo che al soggetto minacciato appaia impossibile, data la imminenza del verificarsi del danno cui il pericolo stesso si riferisca, allontanare tale evento, se non... mediante la attuazione del cosiddetto comportamento necessitato" (PIRAS, 1948, p. 26). ${ }^{25}$

Inoltre, il pericolo non deve essere stato volontariamente provocato dal soggetto necessitato, il che viene inteso da taluni in modo particolarmente rigoroso, sì da escludere interpretazioni che, ampliando eccessivamente l'àmbito di operatività del requisito, riducano al contempo l'efficacia giustificante dello stato di necessità. ${ }^{26}$ Le opinioni contrarie, fondate sul rilievo che lo stato di necessità costituisce un'eccezione al principio della completa risarcibilità dei danni, il che esigerebbe un particolare rigore nella relativa integrazione, si rivelano però contestabili, in quanto la lettera della norma richiede chiaramente l'assenza di coscienza e volontà del pericolo da parte del soggetto necessitato, per cui, in caso di comportamento colposo o di causazione anche involontaria del pericolo stesso da parte di questi, il giudice non deve escludere il ricorso all'art. 2045 c.c., ma procedere a quantificare l'indennità in modo da tenere conto delle suddette circostanze e, conseguentemente, da approssimare il quantum dovuto al risarcimento integrale (pur se la medesima indennità tendenzialmente è sempre inferiore come importo rispetto al risarcimento). Inoltre, si è fatto giustamente notare che una nozione così ampia di volontarietà, la quale sottolinea particolarmente gli elementi oggettivi della causalità tra il pericolo e il danno arrecato a scapito della valutazione della colpevolezza come elemento soggettivo, renderebbe assai difficoltoso giustificare il perché un comportamento incolpevole o comunque estraneo ad attività rischiose o pericolose, pur se causalmente influente per la creazione della situazione necessitata, possa precludere l'applicazione dell'art. 2045 c.c. ${ }^{27}$

Quanto al pericolo esclusivamente supposto ma non reale, che fonda il c.d. stato di necessità putativo, le opinioni che si riscontrano sul punto sono polarizzate in un indirizzo positivo, ove si sostiene comunque l'integrazione della fattispecie necessitante anche qualora essa, pur non effettivamente ravvisabile, appaia comunque sussistere in base a circostanze obbiettive ${ }^{28} \mathrm{e}$ un indirizzo negativo, ove si fa leva sulla eccezionalità dell'art. 2045 c.c., il quale sarebbe applicabile solo là dove i relativi requisiti fossero concretamente presenti (FRANZONI, 2010, p. 1154-1155). ${ }^{29}$ Ora, lo stato di necessità putativo, stante la lacuna disciplinare sul punto, crea una situazione di particolare complessità: da un lato, infatti,

24 S. Piras (1948) adotta un concetto differente di attualità. Nella letteratura penalistica cfr. G. Fiandaca-E. Musco (2014, p. 318), secondo i quali non sempre il criterio temporale, basato sull'imminenza cronologica del danno, consente di determinare correttamente l'attualità del pericolo, poiché talvolta deve agirsi anticipatamente per impedire l'aggravamento delle potenzialità lesive insite nell'azione pericolosa.

25 Si è fatto notare che il suddetto requisito, più che al pericolo, deve essere correlato al danno, sulla base della inesigibilità per il necessitato che questi ponga in essere tutte le cautele idonee a scongiurare il pericolo (così B. Troisi, 1984, p. 17). Cfr. sul punto anche A. Venchiarutti (1988, p. 483), che riporta l'esempio dell'esportazione illecita di valuta da parte di chi intende sottoporre la moglie gravemente malata ad alcune cure mediche all'estero, la quale condotta non integra lo stato di necessità se non verrà provata l'assoluta indilazionabilità della terapia e l'impossibilità di provvedere in modo lecito al pagamento della prestazione. R. Scognamiglio (1968, p. 656) sottolinea opportunamente come sia necessario verificare, in base ad un giudizio particolarmente rigoroso, se al pericolo ci si possa sottrarre altrimenti che sacrificando l'altrui interesse, mediante cioè azioni diverse da quella compiuta, idonee a cagionare un danno sensibilmente inferiore. Tale rigore è richiesto anche per l'integrazione dell'art. 54 c.p., peraltro in termini più rigidi di quanto invece si pretende per la legittima difesa, pur se si sottolinea la necessità di accertare se le condotte alternative in ipotesi attuabili posseggano in concreto pari o analoga idoneità a porre in salvo il bene in questione in confronto al comportamento necessitato (G. FIANDACA-E. MUSCO , 2014, p. 319-320).

26 Di questo avviso è S. Piras (1948, p. 28-29), che propone opportune esemplificazioni, differenziate, nella disciplina applicabile, in base a motivi di logica e di equità nell'interpretazione della lettera della legge. Un approccio esegetico, peraltro assai argomentato, è invece seguito da M. Briguglio (1963, p. 42-46). M. Franzoni (2010, p. 1151-1152), opta per un'interpretazione estensiva del requisito della volontarietà, sì che non solo il fatto doloso o colposo del minacciato, ma anche la sua non estraneità, latamente intesa, alla creazione del rischio gli impediranno di invocare lo stato di necessità. Secondo C. M. Bianca (2012, p. 672), la creazione colposa del pericolo non esime da responsabilità poiché essa rappresenta la causa del danno, ossia la creazione del suo rischio specifico; di conseguenza, il danno risulterebbe causato da un comportamento colposo non necessitato. Anche nella prospettiva del diritto penale si preferisce considerare volontariamente causate le situazioni di pericolo dovute a semplice colpa, con conseguente esclusione della scriminante, in ossequio alla protezione del terzo innocente la quale costituisce la ratio che ha indotto il legislatore a richiedere la volontarietà del pericolo (in tal senso G. Fiandaca-E. Musco, 2014, p. 319).

27 Così B. Troisi (1984, p. 18). Cfr., inoltre, R. Scognamiglio (1968, p. 655-656), secondo il quale per integrare lo stato di necessità deve escludersi la volontà dell'evento-pericolo, da intendersi come un mero fatto psicologico, al di fuori delle qualificazioni in termini di dolo o di colpa che se ne possono prospettare ai diversi effetti della responsabilità.

28 Così M. Briguglio (1963, p. 50-51), che sostiene l'applicazione analogica dell'art. 59, comma $3^{\circ}$ (ora, comma $4^{\circ}$ ), c.p., a tenore del quale se l'agente ritiene per errore (scusabile) che esistano circostanze di esclusione della pena, queste sono sempre valutate a suo favore. Invero tale applicazione analogica risulta alquanto dubbia, trattandosi di norma evidentemente eccezionale, sia nell'àmbito del sistema penale (pur essendo la relativa ratio quella di ampliare la liceità dei fatti astrattamente tipici), sia, a fortiori, nel diverso campo dell'illecito civile. Si veda inoltre B. Troisi (1984, p. 19-21), che risolve il problema della rilevanza civilistica da attribuire allo stato di necessità putativo in base al principio dell'apparenza, a condizione che non si oltrepassino i limiti della c.d. apparenza colposa.

29 Tale opinione si rinviene anche nel diritto francese: cfr. G. Viney - P. Jourdain - S. Carval (2013, p. 665). 
ponendo la relativa fattispecie in rapporto con la corrispondente previsione penalistica (art. $59,4^{\circ}$ co., c.p.), poiché, per l'appunto, lo stato di necessità putativo nel sistema penale è qualificabile come causa di esclusione della colpevolezza, esso, non elidendo l'antigiuridicità del fatto, dovrebbe lasciare intatti gli obblighi risarcitorî; ${ }^{30}$ dall'altro lato, se le circostanze su cui si fonda la putatività sono obbiettive e non derivanti da colpa del necessitato, verrebbe meno il requisito del fatto colposo di cui all'art. 2043 c.c. e non potrebbe pretendersi alcuna riparazione del pregiudizio occorso. ${ }^{31}$ Quest'ultima conclusione, peraltro, produrrebbe una conseguenza paradossale, per cui, quando la situazione necessitante fosse effettivamente sussistente, il danneggiante sarebbe tenuto all'indennità ex art. 2045 c.c., mentre, in caso di stato di necessità putativo, non vi sarebbe alcun risarcimento o indennizzo ${ }^{32}$ da corrispondere. Tali difficoltà esortano ad affrontare il problema in senso conforme alla ratio della disposizione in discorso, la quale, nel bilanciare le esigenze del necessitato e del danneggiato, mostra di volere comunque assicurare a quest'ultimo una parziale compensazione del danno, incolpevolmente subito; ne consegue, allora, l'applicazione analogica dell'art. 2045 c.c., norma speciale ma non eccezionale,$^{33}$ allo stato di necessità putativo, ${ }^{34}$ così da evitare ingiustificate disparità di trattamento e coordinare in modo equilibrato gli opposti interessi. ${ }^{35}$

30 Secondo L. Concas (1969, p. 802-803), le scriminanti putative sono previste nel diritto penale in base ad una valutazione settoriale, per cui esse, in mancanza di un'espressa disposizione, non sono rilevanti per il diritto civile, il quale si ispira ad esigenze di tutela diverse rispetto al diritto penale, neppure quando le corrispondenti scriminanti reali abbiano qualche incidenza sull'esistenza dell'illecito civile o sulle conseguenze ricollegabili ad esso.

31 Merita avvertire in questa sede che, là dove non sia espressamente prevista una ragione particolare per l'uso del termine indennizzo, esso deve ritenersi sinonimo di indennità, pur se si è consapevoli degli argomentati studî con cui la recente dottrina ha investigato i confini semantici ed applicativi delle due nozioni; sul tema rinvio a C. Caricato (2012, p. 203-207), ove, a conclusione della relativa indagine, viene individuata come linea tendenziale di demarcazione tra indennità ed indennizzo il fatto che, mentre la prima è utilizzata in via generale per designare un'allocazione dei costi, conseguenti all'atto dannoso, la quale è svincolata dai rigidi criterî previsti nelle norme in tema di risarcimento del danno, il secondo viene impiegato soprattutto (ma non solo) quando la pretesa alla riparazione da parte del privato incontra pubblici poteri o comunque interessi di natura pubblicistica [il che spiega la constatazione secondo cui l'interprete, nell'ordinare i fenomeni giuridici, può solo osservare il dato testuale ed empirico e tentare di coglierne i tratti comuni.

32 Ciò premesso, non può peraltro sostenersi che l'art. 2045 c.c. sia analogicamente applicabile all'ipotesi di danno cagionato da persona non punibile per avere agito in stato di legittima difesa putativa [in questo senso, invece, si veda Cass. civ., sez. III, 12 agosto 1991 , n. 8772 , in Giur. it., 1992, I, 1, cc. 734-739, con osservazioni di D. Carusi (cc. 733-736), la quale pronuncia, peraltro, nega la natura eccezionale dell'art. 2045 c.c. In dottrina, M. Comporti (2002, p. 17). Cfr., inoltre, l'interessante ricostruzione di G. Giacobbe (2000, p. 64-68), il quale, sul presupposto che le cause di giustificazione non fissano regole eccezionali ma sono espressione di principî generali che l'ordinamento ha previsto per tutelare situazioni simili, ritiene analogicamente applicabile l'art. 2045 c.c. alla legittima difesa putativa, in quanto quest'ultima sarebbe del tutto analoga alla fattispecie dello stato di necessità, in quanto vi è un soggetto che agisce nell'erronea convinzione di essere costretto a salvare sé od altri da un grave pregiudizio (il quale, a differenza di quello contemplato nell'art. 2045 c.c., non necessariamente si riferisce ad un danno grave alla persona), arrecando danno ad un terzo, poiché è senz'altro tale colui che subisce l'aggressione senza avervi dato causa. Sul punto può rilevarsi, anzitutto, che anche la legittima difesa putativa, come tutte le scriminanti putative, pur escludendo l'integrazione del reato non elimina l'antigiuridicità ma la sola colpevolezza, per cui il danno cagionato sarebbe integralmente risarcibile e non compensabile con una mera indennità; nella suddetta ipotesi, allora, o sorge l'obbligo di risarcire integralmente il danno, oppure, se si equipara la legittima difesa putativa a quella oggettiva, non si avrà alcuna conseguenza civilistica, neanche di carattere indennitario. Anche sulla base dell'esigenza, esposta nel testo, di contemperare gli opposti interessi evitando disparità di trattamento infondate, quest'ultima soluzione mi pare quella più rispondente alle caratteristiche della relativa fattispecie. A ciò non varrebbe opporre la similitudine strutturale tra legittima difesa putativa e stato di necessità, in quanto in tal modo verrebbe obliterato il dato essenziale dell'assenza di colpa del soggetto agente nella difesa dalla supposta aggressione, il che, nell'ottica delle cause di giustificazione come espressione di principî generali, deve necessariamente esplicare effetti tali da distinguere la relativa fattispecie dallo stato di necessità (anche putativo), foriero allora di differenti conseguenze civilistiche.

33 Ciò premesso, non può peraltro sostenersi che l'art. 2045 c.c. sia analogicamente applicabile all'ipotesi di danno cagionato da persona non punibile per avere agito in stato di legittima difesa putativa [in questo senso, invece, si veda Cass. civ., sez. III, 12 agosto $1991, \mathrm{n}$. 8772 , in Giur. it., 1992, I, 1, cc. 734-739, con osservazioni di D. Carusi (cc. 733-736), la quale pronuncia, peraltro, nega la natura eccezionale dell'art. 2045 c.c. In dottrina, M. Comporti (2002, p. 17). Cfr., inoltre, l'interessante ricostruzione di G. Giacobbe (2000, p. 64-68), il quale, sul presupposto che le cause di giustificazione non fissano regole eccezionali ma sono espressione di principî generali che l'ordinamento ha previsto per tutelare situazioni simili, ritiene analogicamente applicabile l'art. 2045 c.c. alla legittima difesa putativa, in quanto quest'ultima sarebbe del tutto analoga alla fattispecie dello stato di necessità, in quanto vi è un soggetto che agisce nell'erronea convinzione di essere costretto a salvare sé od altri da un grave pregiudizio (il quale, a differenza di quello contemplato nell'art. 2045 c.c., non necessariamente si riferisce ad un danno grave alla persona), arrecando danno ad un terzo, poiché è senz'altro tale colui che subisce l'aggressione senza avervi dato causa. Sul punto può rilevarsi, anzitutto, che anche la legittima difesa putativa, come tutte le scriminanti putative, pur escludendo l'integrazione del reato non elimina l'antigiuridicità ma la sola colpevolezza, per cui il danno cagionato sarebbe integralmente risarcibile e non compensabile con una mera indennità; nella suddetta ipotesi, allora, o sorge l'obbligo di risarcire integralmente il danno, oppure, se si equipara la legittima difesa putativa a quella oggettiva, non si avrà alcuna conseguenza civilistica, neanche di carattere indennitario. Anche sulla base dell'esigenza, esposta nel testo, di contemperare gli opposti interessi evitando disparità di trattamento infondate, quest'ultima soluzione mi pare quella più rispondente alle caratteristiche della relativa fattispecie. A ciò non varrebbe opporre la similitudine strutturale tra legittima difesa putativa e stato di necessità, in quanto in tal modo verrebbe obliterato il dato essenziale dell'assenza di colpa del soggetto agente nella difesa dalla supposta aggressione, il che, nell'ottica delle cause di giustificazione come espressione di principî generali, deve necessariamente esplicare effetti tali da distinguere la relativa fattispecie dallo stato di necessità (anche putativo), foriero allora di differenti conseguenze civilistiche.

34 Così già M. Briguglio (1963, p. 50-51). M. Comporti (2002, p. 41) ritiene si debba invece discorrere di interpretazione estensiva.

35 In tal senso P. G. Monateri (1998, p. 256), secondo il quale "si appalesa appieno come la norma dell'art. 2045 c.c. non sia solo una salvaguardia del soggetto necessitato, che non deve il risarcimento, ma anche del soggetto sacrificato, giacché fonda e legittima una sua pretesa indennitaria, la quale, altrimenti, non sarebbe varie volte fondabile." 
Di particolare interesse è poi un profilo del pericolo non espressamente menzionato nell'art. 2045 c.c., il quale, però, essendo previsto nell'art. 54 c.p., si ritiene comunque configurabile con riferimento alla fattispecie civilistica: il soggetto su cui il pericolo incombe non deve avere un obbligo giuridico di esporsi ad esso. ${ }^{36}$ Tale obbligo, derivante da fonti di varia natura, se sussistesse, non consentirebbe al soggetto che realizza un fatto dannoso di invocare lo stato di necessità al fine di sottrarsi alla corresponsione dell'integrale risarcimento, sebbene l'art. 2045 c.c. sembri applicarsi, a differenza della causa di giustificazione penalistica, anche a quest'ultima ipotesi. ${ }^{37}$

II riferimento ai "motivi di logica", mediante i quali si avalla l'integrazione della fattispecie ex art. 2045 c.c. con un siffatto elemento implicito (PIRAS, 1948, p. 30-32), ha suscitato riserve che rilevano l'inadeguatezza di soluzioni generalizzanti e, per contro, la necessità di verificare le concrete circostanze del caso (TROISI, 1988, p. 21-23); per vero, da un lato, i motivi di logica sussistono e, dall'altro, l'integrazione della fattispecie normativa con l'assenza di un obbligo giuridico di esporsi al pericolo per il soggetto necessitato non preclude affatto la considerazione delle circostanze prima menzionate. Anzitutto, logica vuole che, se lo stato di necessità privatistico si applicasse alle ipotesi in cui un soggetto ha il dovere di esporsi al pericolo, si verificherebbe una discrasia tra disciplina penale e regolamentazione civile del caso, con inversione rispetto alla fisiologia dei rapporti tra i due settori dell'ordinamento. Difatti, mentre nel diritto penale si avrebbe un reato, in quanto non viene integrata la causa di giustificazione dello stato di necessità per assenza di un suo requisito essenziale, nel diritto civile non si produrrebbe la conseguenza del risarcimento del danno arrecato, conseguenza che, per le ipotesi di reato, è espressamente sancita dall'art. 185 c.p. e che, invece, non sarebbe applicabile alla disciplina civilistica della situazione ipotizzata, poiché in essa non rileva l'art. 2043 c.c. ma l'art. 2045 c.c., contemplante l'obbligazione indennitaria. In sintesi, se vi fosse disomogeneità di contenuti, con riguardo al problema del dovere di esporsi al pericolo, tra norma penale e regola civile, l'area dell'illecito penale sarebbe più ampia dell'area dell'illecito civile, il che frustrerebbe il principio dell'extrema ratio nonché la funzione riparatoria del risarcimento, atteso dalla vittima del reato. Inoltre, poiché una delle critiche citate consiste nel sottolineare l'inesigibilità dell'estremo sacrificio della vita nelle ipotesi di pericolo più significative, pur in presenza di un dovere di esporsi ad esso, tale esigenza viene comunque assicurata dalla struttura stessa del dovere, il quale non può mai essere tale da comportare la rinuncia alla salvaguardia dei beni primarî dell'individuo.

Peraltro, se in presenza di evenienze assai gravi atte a pregiudicarne la persona, il dovere cessa di vincolare il soggetto che recupera la facoltà di ricorrere al comportamento necessitato, è pur vero che il suddetto dovere, qualora fosse strumentale alla tutela di un interesse di altissimo rango, sarebbe anch'esso particolarmente cogente, riducendo corrispondentemente l'àmbito di integrazione dell'art. 2045 c.c., mentre, quando la tutela della propria incolumità imponesse il sacrificio di un interesse inferiore, non potrebbe pretendersi da chi è minacciato dal pericolo la salvaguardia di questo interesse a discapito di se stesso. Volendo esemplificare, un vigile del fuoco che, in presenza di un incendio, rinunciasse a portare in salvo la vittima per non esporsi al pericolo di vita, non potrebbe invocare lo stato di necessità penalistico né l'art. 2045 c.c. qualora non adempisse al suo dovere; se la vittima, però, fosse in una situazione tale da farne disperare la salvezza, sì che il comportamento doveroso del vigile non solo non assicurerebbe la suddetta salvezza ma condurrebbe alla perdita della vita anche del soccorritore, allora in tal caso il dovere di esporsi al pericolo cessa di vincolare quest'ultimo, che andrà esente da responsabilità. Differentemente, se il vigile chiamato ad impedire la distruzione di un edificio sgombro da persone temesse per la propria incolumità, non conoscendo la tenuta strutturale della costruzione, e preferisse abbandonarlo alla furia delle fiamme anziché adoperarsi per garantirne l'integrità, a seconda del livello di pericolo concretamente sussistente una sua eventuale omissione non sarebbe penalmente rilevante (danneggiamento in base al

\footnotetext{
6 Con riferimento all'art. 54 c.p., si è precisato che, nonostante la dizione letterale dell'art. 54 , co. $2^{\circ}$., c.p., la scriminante è comunque applicabile se chi ha un particolare dovere di esporsi al pericolo realizza un'azione necessitata per salvare non se stesso ma terzi in pericolo; per questa conclusione si vedano G. Fiandaca-E. Musco (2014, p. 323).

37 S. Rossi (2012, p. 714) rileva a questo proposito come l'ordinamento, tramite l'art. 2045 c.c., attenui la responsabilità del comune cittadino che agisca in stato di necessità, ma non esima chi, avendo ricevuto uno specifico addestramento ed eventualmente potendo disporre di un idoneo equipaggiamento, sia particolarmente attrezzato per fronteggiare il pericolo.
} 
combinato disposto degli artt. 635 e 40, $2^{\circ}$ co., c.p.), pur se, civilmente, egli potrebbe essere chiamato a corrispondere l'indennità ex art. 2045 c.c.

$\mathrm{Ne}$ consegue che il requisito dell'assenza di un particolare dovere di esporsi al pericolo è presente, in via espressa, nell'art. 54 c.p. e, in via implicita ma logicamente, nell'art. 2045 c.c.; il dovere però, non impedisce al soggetto che ad esso si espone di salvaguardare la propria vita o incolumità fisica mediante una condotta giustificata dallo stato di necessità.

\section{II pericolo cagionato dal fatto illecito del terzo}

Per accertare se l'obbligazione indennitaria possa qualificarsi come un effetto meramente eventuale nella fattispecie dello stato di necessità, si è già anticipato che, qualora il fatto necessitato venga compiuto a séguito del pericolo sorto ad opera di un soggetto "necessitante", questi sarebbe responsabile del danno arrecato ai sensi dell'art. 2043 c.c. ${ }^{38}$ ciò rende opportuno, riprendendo quanto più sopra sommariamente esposto, chiarire il rapporto tra le due obbligazioni del risarcimento del danno (cui sarebbe tenuto il terzo) e della riparazione indennitaria (in capo al pericolante). Si è detto che la ratio stessa dell'art. 2045 c.c., in presenza di un danno integralmente riparabile da parte di colui che ha cagionato il pericolo, impone al giudice di escludere l'indennità, sì che la relativa obbligazione non verrebbe in essere per inconfigurabilità della fattispecie legale ${ }^{39}$ (qualora lo scopo della medesima, da individuarsi nella compensazione che l'ordinamento assicura a chi ha subito danni in virtù del comportamento necessitato, si ergesse a suo requisito intrinseco). Questa affermazione merita di essere comprovata più puntualmente. Anzitutto, non appare sufficientemente argomentata la tesi dominante, in dottrina ed in giurisprudenza, ${ }^{40}$ secondo la quale, pur in assenza di una specifica previsione in merito, vi sarebbe un concorso tra la responsabilità del terzo, ai sensi dell'art. 2043 c.c., e quella del soggetto necessitato; secondo questa tesi, in particolare, il danneggiante sarebbe obbligato a corrispondere l'indennità prevista nell'art. 2045 c.c. ${ }^{41}$ sia se direttamente

8 Di particolare rilievo, in questa prospettiva, è l'argomentazione di B. Inzitari (1977, p. 864), il quale, dopo avere osservato che "tra la creazione della situazione necessitata da parte del terzo colpevole e il danno arrecato dal soggetto che subisce la situazione di pericolo, non esiste una sufficiente continuità di causa ed effetto, in quanto le reazioni psicologiche e le valutazioni di opportunità di quest'ultimo troncano la concatenazione meccanica degli avvenimenti e determinano autonomamente l'an e il quantum della lesione", sottolinea come la legittimazione passiva del solo autore dell'atto necessitato "avrebbe, come indiretta conseguenza, una incisiva limitazione di responsabilità per il terzo: questi potrebbe aver creato gravissimi pericoli e del tutto volontariamente, dalla situazione di pericolo potrebbero essere scaturiti atti necessitati oltremodo dannosi, ma l'indennità attribuita al danneggiato proprio in virtù della gravità del pericolo corso dall'autore del danno potrebbe essere notevolmente esigua, col risultato che i limiti della responsabilità del danneggiante necessitato (art. 2045) si volgerebbero a favore del terzo autore del pericolo, il quale al massimo sarebbe chiamato a indennizzare il danneggiante nella misura del danno da questi subito, cioè con l'indennità ex art. 2045". Questa ricostruzione è significativa, da un lato, della difficoltà di escludere una diretta obbligazione risarcitoria in capo al terzo e, dall'altro, della scarsa efficacia protettiva del danneggiato che il supposto cumulo tra le pretese al risarcimento dal suddetto terzo e all'indennità dal danneggiante aspirerebbe a perseguire.

39 Una siffatta conclusione, che in questa sede si intende rinnovare e consolidare sotto il profilo argomentativo, è stata fatta propria da una risalente giurisprudenza (Cass., 23 agosto 1950, n. 2531, in Resp. civ. e prev., 1950, p. 434-436, con nota di G. Gentile (1950, p. 434-435); Cass., 28 aprile 1951, n. 1032, in Resp. civ. e prev., 1951, p. 125-126; App. Roma, sent. 19 luglio 1948, in Riv. dir. comm., 1949, II, p. 270-274, con nota di R. Corrado (1949, p. 270-274) e da attenta dottrina - N. Distaso (1952); E. Bonasi Benucci (1954, c. 1132), ove si afferma che “ [...] sembra veramente contrario a principi del nostro diritto, una volta individuato l'autore, in senso giuridico, del danno, addossare una sia pur attenuata responsabilità a colui che, solo in senso materiale o naturale, può qualificarsi coautore del danno stesso"; G. Gentile (1954, p. 3-22), che evidenzia come chiamare a concorrere nell'obbligo del risarcimento chi si è trovato strumentalmente ingaggiato in un evento del quale non ha colpa potrebbe nei singoli casi alterare principî tradizionali del nostro diritto; C. Bocca (1954, p.102) sottolinea efficacemente come la speciale obbligazione indennitaria ex art. 2045 c.c. si giustifichi nella sola ipotesi in cui l'evento dannoso non abbia avuto origine dal colpevole operato di terze persone; M. Briguglio (1957, p. 452), ma vedi sul punto Id. (1970, p. 188-193), che, mutando avviso, opta per la soluzione maggioritaria del concorso alternativo tra terzo e danneggiante]. Sul punto merita attenta considerazione quanto affermato da P. G. Monateri (1998, p. 253-254), che sottolinea come il danno sia integralmente riferibile al terzo quando la sua signoria del fatto gli abbia consentito di dominare l'intera serie causale di eventi, mentre anche il danneggiante sarà chiamato a compensare il pregiudizio arrecato, nei limiti dell'indennità, qualora la sua condotta rivesta una propria autonomia. In realtà, se la condotta del danneggiante fosse autonoma rispetto al pericolo creato dal terzo (in quanto solo in tal modo quest'ultimo non avrebbe la signoria sull'intera serie causale di eventi), è dubbio che si possa parlare di stato di necessità, almeno sotto il profilo della inevitabilità del pericolo stesso, dal quale l'azione del supposto necessitato dovrebbe distaccarsi prescindendone, se per l'appunto la si assume come autonoma. $\mathrm{Ne}$ consegue che, nell'ipotesi suesposta, difettando la fattispecie di cui all'art. 2045 c.c., questo non sarebbe invocabile e il danno dovrebbe essere risarcito nella sua interezza; inoltre e a contrario, ciò a mio avviso palesa la necessaria correlazione tra il pericolo cagionato dal terzo e la sua responsabilità esclusiva per il comportamento necessitato, qualora tutti gli elementi indicati nella relativa previsione fossero rinvenibili nella situazione concreta.

40 La struttura di questa argomentazione prende le mosse da Cass. (1952, I, cc. 301-304, con osserv. di A. Scialoja). In dottrina si veda riassuntivamente E. Bonvicini (1971, p. 512-513).

41 M. Comporti (1964, p. 43) ritiene che tale soluzione sia preferibile in quanto realizza il giusto equilibrio tra gli interessi in conflitto, oltre a meglio tutelare la posizione del danneggiato che viene salvaguardato dalla eventuale insolvenza di uno dei soggetti convolti nella vicenda; inoltre, essa trasferisce l'intero onere risarcitorio sul terzo necessitante, in quanto responsabile di tutta la sequenza causale, poiché egli, come si vedrà, sarebbe anche esposto all'azione di rivalsa del soggetto necessitato che abbia corrisposto l'indennità. 
adito dal danneggiato (potendo poi egli rivalersi nei confronti del terzo, che sarebbe allora tenuto verso il necessitato e al contempo verso il danneggiato ${ }^{42}$ ), sia in via residuale, qualora quest'ultimo non avesse ricevuto l'integrale risarcimento e si rivolgesse al necessitato per ottenere la differenza tra quanto effettivamente conseguito dal terzo e l'indennità. ${ }^{43}$

Si tratta, all'evidenza, di una soluzione di carattere equitativo che mira a rafforzare la tutela del danneggiato, sul presupposto della coerenza a tal fine del concorso di responsabilità. ${ }^{44}$ Peraltro, oltre a non corrispondere al sistema, come si tenterà di dimostrare nel prosieguo del ragionamento, questo indirizzo interpretativo non sembra idoneo al raggiungimento dello scopo che si prefigge, poiché è fallace il relativo presupposto. Infatti, affermare sic et simpliciter che, se il terzo non fosse in concreto nelle condizioni economiche idonee a risarcire il danno, allora potrebbe pretendersi (in via sussidiaria?) l'indennità dal necessitato, significa attribuire per l'appunto all'equità, e non al sistema, il compito di fondare il sorgere dell'obbligazione. Inoltre, qualora il pericolo causato dal terzo fosse di rilevante entità, la compensazione indennitaria sarebbe quantitativamente assai esigua, sì che, se lo stesso terzo fosse in tutto o in parte economicamente incapace del ristoro risarcitorio, un'eventuale obbligazione sussidiaria, anche sotto il profilo pratico, non soddisferebbe le ragioni di equità che la teorica in esame attribuisce al cumulo delle azioni verso il pericolante ed il necessitato.

Ancora, tale prospettiva, a mio avviso, ridimensiona eccessivamente la circostanza che, sotto il profilo causale, o il fatto del terzo costituisce un elemento dal quale il danno deriva come conseguenza immediata e diretta, ai sensi degli artt. 1223 e 2056 c.c., e allora solo questi potrà essere chiamato al risarcimento, oppure la condotta del necessitato si pone come causa sopravvenuta idonea da sola a determinare l'evento, interrompendo il nesso eziologico con il pericolo cagionato dal terzo, che andrà esente da responsabilità. ${ }^{45}$ Per le modalità con cui l'azione necessitata viene normativamente descritta, allora, è difficilmente rinvenibile un concorso di cause nella produzione dell'evento dannoso. ${ }^{46} \mathrm{Ne}$ consegue che un'eventuale responsabilità concorrente del necessitato e del terzo, in assenza di un'espressa indicazione legislativa, potrebbe essere legittimata solo dalla ricognizione del sistema.

In quest'ottica, se una situazione che integra lo stato di necessità deriva dal pericolo cagionato da un terzo, la fattispecie codicistica si arricchisce di un ulteriore elemento in essa non contemplato, ${ }^{47}$ il che evidenzia una lacuna nell'art. 2045 c.c., il quale non disciplina la rilevanza di questo elemento poiché non risolve il conflitto tra le posizioni del terzo necessitante, del soggetto necessitato e del danneggiato. La suddetta lacuna esige che il criterio di soluzione del problema si rinvenga in una previsione diversa dalla norma sullo stato di necessità, previsione che contempli l'ipotesi di un fatto astrattamente produttivo delle obbligazioni di risarcimento e indennità e che risolva il conflitto di interessi sotteso a questa ipotesi nell'ottica del principio di corrispondenza della riparazione al danno. Nel caso in discorso, allora, una simile norma, da applicare analogicamente, può ravvisarsi nell'art. $2047,2^{\circ}$ co., c.c., che costituisce a mio avviso una regola ${ }^{48}$ suscettibile di disciplinare tutte le fattispecie in cui il risarcimento del danno, seppure astrattamente

42 E. Bonvicini (1971, p. 513) parla di un'azione autonoma, non di regresso, verso il terzo autore dello stato di pericolo per la somma eventualmente corrisposta a titolo di indennità.

43 Cfr. per questa opinione R. Scognamiglio (1968, p. 656) e, in giurisprudenza, Cass., 8 settembre 1978, n. 4074, in Foro it., 1979, I, cc. 1031-1034, con sintesi bibliografica e di precedenti (cc. 1031-1032) ed osservazioni di E. De Leo (c. 1032), secondo la quale risarcimento e indennità, seppure non cumulabili, sono per l'appunto integrabili.

44 Cfr. M. Comporti (1964, p. 238), per cui non può negarsi all'equità il ruolo di criterio di imputazione della fattispecie di cui all'art. 2045 c.c., respingendo in tal modo l'opinione di S. Rodotà (1964, p. 143), che attribuisce all'equità l'esclusivo compito di determinare l'ammontare dell'indennizzo e non di stabilire se questo sia dovuto. Mi pare che, prima di rinvenire un fondamento equitativo dell'obbligazione, sia invece doveroso verificare se la medesima possa essere giustificata in modo più aderente al dettato normativo, al di là della censura che in tal modo ci si manterrebbe "al livello del puro dato formale delle norme" (M. Comporti, 1964, p. 238)

45 In effetti le argomentazioni sul punto solitamente trascurano la positiva disciplina del rapporto di causalità, pur se il trasporre i principî penalistici in materia non pare sempre opportuno (cfr., per un richiamo agli artt. 40 e 41 c.p., A. R. Latagliata (1953, p. 171).

46 Cfr. A. Violante (1983, p. 1269, secondo il quale le azioni risarcitoria e indennitaria non sarebbero cumulabili, poiché tra la disciplina del fatto illecito e quella dello stato di necessità vi sarebbe un rapporto regola-eccezione. Di diverso avviso è E. Bonvicini (1971, p. 512), secondo il quale tra il fatto illecito del terzo e il danno subito dalla vittima si inserisce come causa concorrente il comportamento necessitato del soggetto in pericolo.

47 A differenza di quanto avviene, ad esempio, nel codice civile portoghese, dove si prevede espressamente all'art. $339 .^{\circ}, 2^{\circ}$ co., la responsabilità principale di chi fa insorgere il pericolo; cfr. sul punto A. Diurni (2003, p. 251), per gli opportuni rilievi comparatistici, nonché P. De Lima - A. Varela (2010, p. 303).

48 Trattasi in particolare di regola speciale ma non eccezionale; per un'opinione diversa cfr. L. Corsaro (1976, p. 16), ove si afferma che l'art. 2047, co. $2^{\circ}$, c.c. sarebbe invece una norma eccezionale. 
configurabile, non sia satisfattivo per il danneggiato, lasciando così al giudice il potere di stabilire a favore di questi almeno una compensazione indennitaria a carico del soggetto che, pur non essendo responsabile per difetto dei requisiti di cui all'art. 2043 c.c., abbia tenuto una condotta comunque connessa al fatto del danneggiante ${ }^{49}$ : l'art. $2047,2^{\circ}$ co., c.c., infatti, dispone che, se non fosse possibile ottenere il risarcimento da chi era tenuto alla sorveglianza dell'incapace, quest'ultimo possa essere chiamato per l'appunto a corrispondere un'indennità. ${ }^{50}$ Dal relativo precetto, letto a contrario, si ricava che, se può adempiere alla propria obbligazione chi è vincolato al risarcimento, quella indennitaria non sorge in capo all'altro soggetto coinvolto nella fattispecie. Con riferimento al problema che ci occupa, di conseguenza, a fronte del pericolo cagionato dal terzo, l'obbligazione indennitaria si costituisce esclusivamente qualora non fosse possibile per il danneggiato conseguire un ristoro totale del pregiudizio subìto: più propriamente, nei suddetti casi l'indennità, secondo l'applicazione analogica dell'art. $2047,2^{\circ}$ co., c.c., non è obbligatoria ma deve corrispondersi solo nel momento in cui il soggetto chiamato a risarcire il danno non fosse economicamente capace di assolvere la propria obbligazione.$^{51} \mathrm{II}$ differente tenore dell'art. 2047 , co. $2^{\circ}$, c.c. ("[...] il giudice... può condannare l'autore del danno ad una equa indennità") rispetto all'art. 2045 c.c. ("[...] al danneggiato...è dovuta un'indennità") è poi spiegabile in base al fatto che, nel primo caso, si è di fronte ad un atto non tipico (quindi, non corrispondente alla previsione dell'art. 2043 c.c.) per difetto della suitas, il che rende meno stringente una redistribuzione delle conseguenze pregiudizievoli cagionate dalla condotta dannosa tra il suo autore e colui che le ha subite..$^{52}$ Inoltre, giova all'applicazione analogica dell'art. 2047, co. $2^{\circ}$, c.c. ${ }^{53}$ l'equiparazione tra l'assenza di capacità naturale, menzionata al primo comma di questa norma, e la particolare limitazione delle facoltà volitive che il necessitato subisce a séguito del pericolo: se quest'ultimo deriva da eventi naturalistici, esso giustifica l'inderogabile sorgere dell'obbligo di corrispondere l'indennità come unico ristoro possibile per il danno cagionato, mentre, se origina per il fatto del terzo, rende eventuale la compensazione indennitaria confinandola ai soli casi di mancata soddisfazione del danneggiato per incapacità economica al risarcimento del soggetto necessitante..$^{54}$

Accedendo alla proposta interpretativa qui formulata, si eviterebbero una serie di problemi di coordinamento tra le due obbligazioni, risarcitoria e indennitaria, ${ }^{55}$ le quali, anzitutto, pur se si accettasse

49 M. Comporti (2002, p. 199) parla a tale proposito della "attribuzione alla vittima di un diritto a sollecitare la decisione discrezionale del giudice sull'an e sul quantum della riparazione, entrambi parimenti subordinati all'apprezzamento equitativo delle condizioni economiche delle parti”.

50 In tale caso l'obbligazione dell'incapace, oltre ad essere eventuale, avrebbe carattere sussidiario, rispetto a quella principale del sorvegliante e la sua natura indennitaria ne escluderebbe l'equivalenza con l'integrale riparazione del danno, come rileva M. Comporti (2002, p. 199).

51 Va peraltro precisato che, oltre all'insolvenza, ai fini dell'applicazione dell'art. 2047 , co. $2^{\circ}$., c.c., vi possono essere ulteriori ragioni per il mancato risarcimento da parte di chi è tenuto alla sorveglianza dell'incapace, come la prova di non avere potuto impedire il fatto, oppure, come chiarito dalla giurisprudenza (Cass., 28 gennaio 1953, n. 216, in Giur. it., 1953, I, 1, cc. 496-503, con nota di A. Travi, Indennizzo dovuto dall'incapace, ivi, cc. 497$500)$, l'assenza in concreto di una persona tenuta alla sorveglianza; in tal senso cfr. M. Comporti (2002, p. 198), nonché C. Caricato (2012, p. 86). Per la relativa interpretazione analogica, peraltro, solo l'insolvenza può essere presa in considerazione, non potendo ravvisarsi in tema di stato di necessità le altre situazioni sopra indicate.

52 A differenza di quanto si verifica nello stato di necessità, in cui, pur in presenza di circostanze particolari, in capo al necessitato, affinché si applichi l'art. 2045 c.c., deve sempre riscontrarsi la capacità di intendere e di volere.

53 La quale dovrebbe comunque basarsi sulla eadem ratio che si è cercato di individuare in precedenza; peraltro, anche chi rinviene sia nello stato di necessità sia nel fatto dell'incapace ipotesi di responsabilità civile in senso tecnico, non esita a porre in collegamento le relative fattispecie in base al fatto che entrambe contemplano l'indennità come moderazione del quantum della risposta riparatoria, in virtù di particolari circostanze o della peculiare condizione delle parti. Cfr. in tal senso C. Caricato (2012, p. 18), ove si evidenzia la sostanziale omogeneità delle figure derivante dal rilievo che in entrambe assume il dovere di mutua comprensione e di contribuzione, oltre alla collocazione sistematica di entrambe le norme nel Titolo IX del libro quarto del codice civile.

54 Peraltro, anche con riferimento all'art. 2047 , co. $2^{\circ}$, c.c. si è precisato che il giudice non potrebbe sottrarsi all'applicazione della norma, e comminare così l'indennità, qualora il danneggiato abbia dato prova dei requisiti previsti dalla legge (così L. Corsaro (1976, p. 17). Seguendo tale lettura vi sarebbe un ulteriore punto di raccordo tra l'obbligo compensativo del necessitato e l'indennità dovuta dal danneggiante incapace.

55 I quali problemi, si afferma, non sarebbero sussistenti anche qualora si accedesse all'opinione che ascrive il fatto necessitato all'esclusiva responsabilità del suo autore, poiché la relativa condotta trova, nel pericolo cagionato dal terzo necessitante, solo un'occasione per dispiegarsi, sì che questo pericolo non interrompe il nesso causale tra comportamento necessitato e danno cagionato; per questa proposta interpretativa si veda A. R. Latagliata (1953, p. 171-172). Da ciò deriva, con serrata logica, che al danneggiato spetterebbe esclusivamente l'equa indennità, corrisposta la quale il soggetto necessitato potrebbe agire, ex art. 2043 c.c., verso il terzo necessitante per vedersi risarcire il danno subìto in séguito alla corresponsione del quantum indennitario. Peraltro, ragionando in tal modo, seppure sarebbe condivisibile il riferimento al nesso causale tra fatto necessitato e danno - in quanto, rispetto al pericolo prodotto dal necessitante, detto fatto si porrebbe come circostanza successiva che, da sola, sarebbe idonea a cagionare l'evento, se si individua il parametro di accertamento del nesso causale nell'art. 41, $2^{\circ}$ co., c.p. (così A. R. Latagliata, 1953, p. 172) - non si terrebbe conto del fatto che il terzo pone in essere un fatto illecito e che quindi sarebbe iniquo esonerarlo da una responsabilità che, in altre circostanze, avrebbe comportato l'obbligo di un integrale risarcimento in capo al medesimo (così G. Giacobbe, 2000, p. 103). Invero, l'opinione succitata tiene conto del fatto che il terzo commette un illecito, ma ravvisa il destinatario del medesimo nel solo soggetto necessitato e non nel danneggiato "finale", ciò in quanto essa sposa una lettura del nesso causale eccessivamente restrittiva; in particolare, non si considera che, in termini probabilistici e di "adeguatezza", il pericolo è idoneo a indirizzare verso l'evento dannoso il comportamento di colui sul quale incombe, specie se si pone mente in tal senso al requisito della inevitabilità. In quest'ultima prospettiva si veda D. Rubino (1970, p. 489), il quale osserva che "l'atto del terzo può essere considerato causa diretta del danno, in quanto a sua volta è stato causa diretta ed esclusiva dell'atto necessitato, che diversamente non si sarebbe verificato (ancora una volta causa causae est causa causati)". 
la teoria del concorso, non sono qualificabili come solidali poiché presentano un oggetto differente; ${ }^{56}$ il diverso quid, allora, impedisce il ricorso alla previsione dell'art. 1293 c.c., ove si afferma che la solidarietà non è esclusa dal fatto che i debitori siano tenuti ciascuno in modo diverso (previsione che, per l'appunto, comprende l'àmbito del quomodo). ${ }^{57}$ Inoltre, in quanto non solidali, le stesse obbligazioni non sono regolate dall'art. 2055 c.c. ${ }^{58}$ il quale sancisce, per l'appunto, la solidarietà tra i corresponsabili del fatto illecito (realizzato dal solo soggetto necessitante, mentre per quello necessitato vale la giustificazione ex art. 2045 c.c.). La norma, in particolare, non sarebbe operativa con specifico riguardo alla ripartizione, nei rapporti interni e mediante regresso, del costo del risarcimento, poiché non è applicabile né il criterio della gravità della rispettiva colpa (art. 2055, co. $2^{\circ}$, c.c.) né la presunzione di eguaglianza delle colpe stesse (art. 2055 , co. $3^{\circ}$, c.c.), e non solo in riferimento ai rapporti tra necessitato e necessitante, ma anche a quelli eventualmente ipotizzabili tra più necessitati, per assenza dell'elemento soggettivo che funge da presupposto della previsione in commento. ${ }^{59}$

Qualora il danneggiato agisse per l'indennità, in presenza di un danno riconducibile al solo terzo, si pone l'alternativa tra la corresponsione della medesima da parte del necessitato, ${ }^{60}$ la chiamata in causa a scopo di garanzia del necessitante, ex art. 106 c.p.c., sì che da questi il convenuto venga tenuto indenne, ovvero il rigetto della domanda ad opera del giudice, qualora il necessitato provasse in giudizio la provenienza dal terzo del pericolo determinante il comportamento dannoso. ${ }^{61}$ Quest'ultima soluzione, che a me pare più coerente rispetto alla ratio della disposizione civilistica, come sopra ricostruita, comporta, nel caso di incapienza del patrimonio del terzo rispetto all'obbligazione risarcitoria, una forma di beneficium excussionis a favore del soggetto necessitato, il quale, si è detto, sarebbe chiamato a prestare la somma dovuta a titolo di indennità esclusivamente in via sussidiaria. ${ }^{62}$ Un ulteriore profilo problematico attiene al risarcimento parziale eventualmente corrisposto dal terzo: se tale risarcimento, pur non integrale, fosse comunque superiore all'indennità (poniamo che il risarcimento sia pari a 10, l'indennità pari a 5 e quanto corrisposto dal terzo responsabile pari a 7), potrebbe il danneggiato chiedere al soggetto necessitato la corresponsione del residuo (nell'esempio, pari a 3), così da conseguire l'integrale riparazione del danno, nonostante il fatto che, qualora avesse agito per la sola indennità, avrebbe conseguito un minus rispetto alla prestazione risarcitoria, seppure parziale, effettivamente corrispostagli? Seguendo l'impostazione qui accolta, la risposta sarebbe ovviamente negativa.

\section{II comportamento necessitato}

Tenendo conto delle ipotesi pratiche in cui può realizzarsi il comportamento necessitato, le relative caratteristiche sono classificabili in una quadruplice ripartizione, ordinata secondo una scala di gravità

56 Chiarisce ottimamente il punto A. Diurni (2003, p. 248-249). Cfr. inoltre, in termini generali, F. Gambino (2015, p. 574), in cui peraltro, anche con riguardo al dato sistematico fornito dall'art. 2055 c.c., si esclude la "medesima prestazione" dal novero degli elementi della fattispecie della solidarietà, ravvisandovi "un carattere specifico della disciplina normativa, che nell'art. 1292 c.c. enuncia una modalità di attuazione dell'obbligazione con pluralità di soggetti".

57 Secondo M. Franzoni, (2010, p. 1169-1170), la natura solidale dell'obbligazione non presuppone l'unitarietà dell'azione o del titolo della responsabilità, ma l'identità del fatto dannoso, dal che conseguirebbe la possibilità per il danneggiato di rivolgersi indifferentemente nei confronti del terzo e verso il necessitato, la cui responsabilità, peraltro, è limitata all'importo dell'indennità. Tale ricostruzione, a mio avviso influenzata dall'opinione dell'Autore circa la natura giuridica della responsabilità per il fatto necessitato, intesa come "una figura di responsabilità civile tipica, di fonte equitativa, con la quale si tende a realizzare un equo contemperamento degli interessi delle parti in conflitto", si scontra con il rilievo del carattere indefettibile che l'identità della prestazione riveste come presupposto della solidarietà.

58 In tal senso si veda B. Inzitari (1977, p. 865), ove inoltre si afferma, persuasivamente, che "si potrebbe sostenere, forse, una solidarietà limitata quantitativamente entro la minor somma dovuta dal danneggiante necessitato, ma quand'anche questo principio fosse ammissibile, entro questi ristretti limiti ne sarebbe sostanzialmente frustrata gran parte della sua rilevanza pratica: infatti, per il danneggiato non si allargherebbe la sfera di esigibilità del risarcimento del danno (oltre che nei confronti del terzo anche nei confronti del danneggiante necessitato), ma più limitatamente si allargherebbe solamente la sfera di esigibilità della indennità (oltre che nei confronti del danneggiante necessitato, anche nei confronti del terzo)".

59 In tal senso anche D. De Strobel (1965, p. 346); E. Bonvicini (1971, p. 513).

60 II che, per i fautori della teoria del concorso, attiverebbe la duplice responsabilità del terzo, nei confronti del danneggiato per l'intero danno subìto, e nei confronti del danneggiante necessitato, per il quale il quantum sarebbe per l'appunto quello dell'indennità dovuta ex art. 2045 c.c. al soggetto leso; così B. Inzitari (1977, p. 865)

61 Pur se sarebbe applicabile in materia l'art. 269 , co. $3^{\circ}$, c.p.c., in base al quale, se a séguito delle difese svolte dal convenuto nella comparsa di risposta, sia sorto l'interesse dell'attore a chiamare in causa un terzo, l'attore può chiedere al giudice di esserne autorizzato, nel rispetto delle decadenze previste dalla norma.

62 Peraltro, applicando analogicamente l'art. 2047 , co. $2^{\circ}$, c.c., se il danneggiato conseguisse dal terzo un risarcimento solo parziale, il giudice potrebbe condannare il pericolante a corrispondere l'indennità in tutto o in parte (così, per i rapporti tra danneggiato, sorvegliante e incapace, L. Corsaro (1976, p. 17). 
decrescente del danno arrecato: a) distruzione od eliminazione del bene cui si riferisce un diritto soggettivo o, più genericamente, una posizione giuridica altrui; $b$ ) danneggiamento materiale del bene cui l'altrui posizione giuridica si riferisce; $c$ ) lesione di un diritto reale facente capo ad altro soggetto, cioè ingerenza riguardo al bene cui il diritto si riferisce; $d$ ) omissione, da parte del soggetto necessitato, di un dato comportamento cui esso sia tenuto in forza di un rapporto obbligatorio non avente origine negoziale (PIRAS, 1948, p. 4852). ${ }^{63}$ L'inquadramento della condotta in discorso risulta peculiare, in quanto, oltre alla qualifica in termini di negozio giuridico, se ne respinge anche la riconduzione al genus degli atti giuridici in senso stretto, poiché non si ritiene sufficiente a tale proposito né la volontarietà né la produzione di effetti giuridici come conseguenza del comportamento necessitato; la nozione di atto giuridico in senso stretto, in particolare, sarebbe limitata alle pronunce, manifestazioni o dichiarazioni di mero contenuto psicologico, cioè sia di volontà, sia di rappresentazioni, sia di sentimenti. Si preferisce, allora, discorrere di atti materiali, ${ }^{64}$ posti in essere in funzione del potere di arrecare un danno ad altri65 che il soggetto necessitato (o chi per lui) esercita al fine di respingere il pericolo incombente sulla propria persona (PIRAS, 1948, p. 54). Di certo, il comportamento necessitato rilevante ai sensi dell'art. 2045 c.c., dal quale, conseguentemente, scaturisce l'obbligo di corrispondere un'equa indennità, deve essere riconducibile in astratto all'art. 2043 c.c. (che non opera, per l'appunto, a motivo della causa di giustificazione), così partecipando della medesima struttura del fatto illecito; 66 laddove, invece, l'azione sia stata diretta non a cagionare un danno ma, all'opposto, unicamente a giovare al soggetto in pericolo, non si produrranno obblighi compensativi neanche in termini di conseguenze indennitarie. ${ }^{67}$

Quanto al motivo del comportamento necessitato, ossia il respingere il pericolo attuale di un danno grave alla persona, taluno lo accosta ai motivi nei negozî giuridici per evidenziare il peculiare rilievo ad esso attribuito dalla legge, a testimonianza del mutamento di prospettiva che il codice civile del 1942 ha palesato rispetto al precedente codice Pisanelli, ove il motivo era considerato irrilevante nel campo del diritto privato (PIRAS, 1948, p. 55-56). In particolare, si giunge alla conclusione che il legislatore ha elevato il motivo pratico e costante nella sua normalità del comportamento necessitato a requisito normativamente previsto nella fattispecie ex art. 2045 c.c. e valutato in senso positivo dalla suddetta disposizione (PIRAS, 1948, p. 56-57). Peraltro, va precisato che la produzione del danno non costituisce il motivo del comportamento necessitato, ma esclusivamente il mezzo mediante il quale ottenere lo scopo tipizzato dal legislatore, ossia il raggiungimento della salvezza. ${ }^{68}$

63 Nell'ipotesi sub $d$ ), peraltro, si integrerebbe una responsabilità per inadempimento di obbligazioni, allora al di fuori dell'àmbito applicativo dell'art. 2045 c.c., come verrà illustrato infra, al par. 7.

64 Sulla relativa nozione si veda Santi Romano (1983, p. 5-6).

65 A tale conclusione, sintetizzabile nel sorgere di un "droit de nuire à autrui contre indemnité", giunge R. Savatier (1939, §§ 98-107, p. 125-138), che intitola in tal modo la Section VII del Chapitre III (dedicato alla Violation du devoir général de ne pas nuire à autrui), riprendendo quanto in precedenza argomentato in Id. (1970); questa teoria, sulla quale si sono appuntate le critiche di R. Pallard (1950, p. 322-323), e di A. Pirovano (1966, p. 215-216), è considerata non dissimile dalla espropriazione per motivi di utilità privata come ratio dello stato di necessità secondo G. Viney - P. Jourdain - S. Carval (2013, p. 670). Su tale prospettiva vedi il mio Profili critici dello stato di necessità nel diritto privato, cit., par. 3). Recentemente si v. anche B. Girard (2015, \$\$ 225-227, p. 240-243), la quale sottolinea come la nozione del droit de nuire non possieda una vocazione esplicativa ma solo descrittiva, il cui merito esclusivo consiste nel delineare le ipotesi nelle quali l'autore di un danno non è civilmente responsabile, senza fornire la ragione di tale irresponsabilità né una tassonomia delle situazioni in cui si ha il diritto di nuocere ad altri.

66 Da ciò si fa derivare la comune illiceità della condotta giuridica posta in essere dal soggetto agente, il quale cagionerebbe un danno ingiusto in entrambe le ipotesi, con la differenza che, nelle fattispecie riconducibili all'art. 2043 c.c., sussisterebbe il requisito della colpa, laddove, invece, esso non sarebbe rinvenibile nello stato di necessità ex art. 2045 c.c., come afferma C. Caricato (2012, p. 48-49). A tal proposito, può sottolinearsi la particolare importanza che riveste il problema dell'elemento soggettivo del comportamento necessitato, il quale rileva ai fini della produzione dell'obbligo indennitario nei termini dell'intento perseguito e, congiuntamente, esclude qualunque attribuzione del suddetto obbligo a titolo di responsabilità oggettiva. Rinvio per questi aspetti alle precisazioni svolte nel mio Profili critici dello stato di necessità nel diritto privato, cit., par. 3.

67 Con riguardo all'elemento della intenzionalità del danno come conseguenza del comportamento necessitato, per l'applicazione dell'art. 2045 c.c., si veda Cass., 14 ottobre 1969, n. 3322, in Resp. civ. e prev., 1970, pp. 551-553. Sul punto, peraltro, la giurisprudenza ha ritenuto rilevante, ai fini dell'integrazione della fattispecie necessitata, anche la valutazione delle regole di diligenza professionale, applicando lo stato di necessità, sul presupposto di una condotta contraria alle regole di comune prudenza, nell'ipotesi di una brusca frenata alla quale il conducente di un autobus sia stato costretto per l'improvvisa conversione di un altro veicolo (così Cass., 28 settembre 1971, n. 2660, in Riv. giur. circ. e trasp., 1973, c. 268), mentre, quando il guidatore di una vettura privata rechi pregiudizio, in virtù della medesima manovra adottata nelle stesse circostanze, al trasportato a titolo di cortesia, la condotta lesiva non è stata considerata alla stregua di un'azione dannosa (Cass., 3 aprile 1980, n. 2206, con massima in Resp. civ. e prev., 1980, p. 731). Una siffatta diversa conclusione per fattispecie concretamente similari si spiega - a volere tacere il fatto che nella prima ipotesi si versa in un inadempimento dell'obbligazione di trasporto e, pertanto, nella responsabilità contrattuale - per l'appunto sottolineando il differente livello di cura e attenzione che si richiede al vettore professionista rispetto al homo eiusdem condicionis et professionis, la cui reazione istintiva è invece riconducibile nell'alveo del caso fortuito.

68 Così M. Briguglio (1963, p. 98-101). Secondo R. Scognamiglio (1968, p. 656), l'atto necessitato è caratterizzato dal fine di salvataggio oggettivamente inteso, non richiedendosi alcun particolare connotato o movente psicologico. 
Un ulteriore aspetto problematico, che si rinviene dall'analisi della situazione necessitante intesa in senso stretto ma che rileva a séguito dell'attuazione del comportamento necessitato, attiene particolarmente alle posizioni lese da questa condotta, sussistenti in capo ad altro o ad altri soggetti, ${ }^{69} \mathrm{e}$ concerne l'assenza, nell'art. 2045 c.c., di qualsivoglia menzione alla proporzionalità tra il fatto e il pericolo, proporzionalità espressamente indicata, invece, all'art. 54 c.p. ${ }^{70}$ tra i requisiti cogenti per integrare la causa di giustificazione dello stato di necessità. ${ }^{71}$ In tale àmbito, la scelta omissiva compiuta dal legislatore civile è stata avallata sottolineando il "maggiore peso e valore attribuito nel nuovo codice civile al principio fondamentale della integrità e della dignità della persona umana". In specie, di fronte ad un pericolo incombente sugli attributi della persona(lità), nessuna proporzione potrebbe e dovrebbe ricercarsi; si osserva, difatti, come tale pericolo prevalga senz'altro rispetto agli interessi di natura eminentemente patrimoniale che l'azione necessitata può ledere, mentre, nel momento in cui esso minaccia diritti omogenei rispetto a quelli tutelabili mediante lo stato di necessità, si verserà in questa ipotesi in una duplice situazione necessitata, ove il destinatario dell'azione è legittimato a reagire ad essa per respingere il pericolo qualificato di un danno grave alla propria persona (PIRAS, 1948, p. 41). In effetti, il mancato richiamo, nella previsione civilistica, della proporzionalità tra fatto e pericolo che integra, invece, la scriminante penale, si rivela consapevole e sistematicamente sostenibile proprio facendo riferimento a quest'ultima disciplina. ${ }^{72}$ Difatti, se lo stato di necessità di cui all'art. 54 c.p. è comprensivo di una pluralità di fattispecie, ${ }^{73}$ che si articolano come stato di necessità giustificante, il quale elimina l'antigiuridicità, e stato di necessità scusante, che esclude

69 II formante dottrinale e il diritto pretorio francese concordano nel ritenere integrato lo stato di necessità anche dall'utilità sociale del fatto dannoso, "le choix fait par le défendeur entre l'intérêt qu'il a sacrifié et celui qu'il a voulu sauver étant objectivement justifié", con ciò richiedendosi una comparazione tra gli interessi in conflitto, che si rivela particolarmente delicata specie qualora i medesimi non fossero della stessa natura [cfr. per i riferimenti G. Viney - P. Jourdain - S. Carval (2013, p. 666-668)]. Peraltro, il bilanciamento di interessi, che tante perplessità ha suscitato come tecnica di valutazione dell'ingiustizia del danno (sul punto, oltre alle puntuali critiche di C. Castronovo (2006, p. 26-30), e di F. Piraino (2005, p. 729-735), si v. da ultimo l'attenta ricostruzione di N. Rizzo (2015, p. 307-309 e, per la retorica del bilanciamento da parte della giurisprudenza, p. 323-327) non diviene utile a mio avviso neppure se inteso come criterio di integrazione della sua giustizia, da intendersi nel senso di non risarcibilità ex art. 2043 c.c. del medesimo (ultimativo e condivisibile l'esito dell'indagine di N. Rizzo (2015, p. 352), secondo il quale il bilanciamento degli interessi è soltanto "una formula retorica tesa, da un lato, a legittimare, con riferimento alla tecnica di argomentazione usata dal giudice costituzionale, dall'altro a celare una argomentazione sull'ingiustizia del danno che, pur ammantata dai richiami alla regola di correttezza o al principio costituzionale di solidarietà, rivela una natura sostanzialmente equitativa, espressione di un giudizio di valore del suo autore"). Qui può farsi utilmente applicazione della terza ipotesi alternativa che compare nella tassonomia proposta da C. Castronovo (2006, p. 29-30), ove al diritto del danneggiato si contrappone quello dell'agente e che si regola in base al modello dell'esercizio del diritto, in quanto causa di giustificazione, a meno che del medesimo non si abusi anziché renderlo funzionale all'interesse del titolare. Nello stato di necessità, difatti, si contrappongono due diritti, quello in pericolo contemplato nella situazione necessitante e quello offeso dal comportamento necessitato; il criterio di soluzione del conflitto è determinato a priori dal legislatore, che consente, in presenza dei requisiti di cui all'art. 2045 c.c., di tutelare la propria persona anche sacrificando un diritto altrui, il quale deve essere di rango pari o inferiore a quello tutelato (difatti, se fosse di grado superiore, si è già detto, lo stato di necessità privatistico non sussisterebbe, dovendo l'agente risarcire il danno ai sensi dell'art. 2043 c.c.). Ne consegue che in questo àmbito nessun bilanciamento può essere operato dal giudice, il quale si limita a fare applicazione del parametro legale. Merita allora concordare con chi sottolinea che "il processo dialettico di bilanciamento degli interessi non dà forma al giudizio di responsabilità né nelle pronunce dei giudici né nelle argomentazioni degli studiosi: alla base della creazione di nuovi doveri vi è spesso, in realtà, un'istanza equitativa, di giustizia del caso concreto" (così N. Rizzo, 2015, p. 327).

70 La proporzionalità come requisito della fattispecie esimente nell'àmbito penalistico viene accertata non solo in base al raffronto del valore dei beni in conflitto, ma anche tenendo conto dei rischi rispettivamente incombenti, in base ad un accertamento ex ante, sul bene da salvaguardare e su quello del terzo che viene aggredito. Difatti, dall'esame comparativo così integrato può ricavarsi in sede di giudizio il criterio-base per cui, quando il rischio maggiore è quello gravante sull'interesse del terzo innocente, il rapporto di valore tra i beni deve essere proporzionalmente a vantaggio di quello da salvaguardare, mentre, quando il bene di maggiore peso è quello aggredito, il rapporto tra i rischi deve essere proporzionalmente a vantaggio di quello salvaguardato (così G. Fiandaca-E. Musco, 2014, p. 321-322).

71 M. Briguglio (1963, p. 101) fa opportunamente notare come nel nostro ordinamento si sia verificato l'opposto di ciò che poteva riscontrarsi nel sistema tedesco, ove il § 54 dello St.G.B. [sul cui fondamento si vedano i cenni di C. Aiello (1993, p. 12-13)] non menzionava il requisito della proporzionalità, che invece risulta presente nel B.G.B., sia al § 228 ("und der Schaden nicht ausser Verhältnis zu der Gefahr steht") sia, e più intensamente, nel § 904 ("und der drohende Schaden gegenüber dem aus der Einwirkung dem Eigentümer entstehenden Schaden unverhältnissmässig gross ist"). Nell'attuale formulazione dello stato di necessità penalistico in Germania, al § 34 dello St.G.B., si rinviene invero un riferimento all'adeguatezza del fatto come mezzo per scongiurare il pericolo (in base a questa norma lo stato di necessità giustificante è integrato a condizione che "die Tat ein angemessenes Mittel ist, die Gefahr abzuwenden").

72 Cfr., però, B. Troisi (1984, p. 23-26), secondo il quale dovrebbe instaurarsi una relazione di proporzionalità tra il bene sottratto al pericolo e il bene leso, evitando di considerare entrambi nella relativa rappresentazione patrimoniale (p. 25). In tal modo si replica all'opinione di B. Inzitari (1977, p. 860), il quale - sulla base della difficile comparabilità tra bene sottratto al pericolo e bene leso nel diritto civile, in quanto appartenenti a sfere profondamente diverse di valutazione giuridica, ossia, da un lato, il bene persona (in pericolo), dall'altro non i beni in quanto tali, ma la loro rappresentazione patrimoniale - ritiene inapplicabile allo stato di necessità ex art. 2045 c.c. il requisito della proporzionalità (a differenza di quanto avviene nel diritto penale, ove i due beni, essendo omogenei, giustificano il suddetto requisito). Si veda, inoltre, M. Comporti (2002, p. 25-27), il quale, nell'affrontare il problema, accoglie la soluzione integrativa sulla base della proporzionalità come principio generale valevole anche nella materia civilistica, indipendentemente dal richiamo all'analogia.

73 Cfr. nella letteratura penalistica sul punto E. Mezzetti (2000, p. 145-151), che infatti discorre dell'art. 54 c.p. come di una "norma a più fattispecie". 
la colpevolezza come rimproverabilità del fatto, ${ }^{74}$ in dipendenza di tali fattispecie si producono effetti differenti nel campo civilistico: allo stato di necessità giustificante si applica coerentemente l'art. 2045 c.c., mentre lo stato di necessità scusante, proprio in quanto tale, preclude la sanzione penale ${ }^{75}$ ma implica la responsabilità extracontrattuale, sì che, allora, il fatto commesso e scusato penalmente integrerà un illecito civile ex art. 2043 c.c.. ${ }^{76}$ Lo stato di necessità giustificante, inoltre, si basa, nel rapporto tra fatto e pericolo, su una proporzione tra questi elementi ove il pericolo minaccia un bene di valore superiore o eguale a quello sul quale il fatto va ad incidere, mentre lo stato di necessità scusante vede tale rapporto invertito (per cui il fatto ha leso un bene giuridico di rilievo maggiore rispetto a quello minacciato dal pericolo, come ad esempio il danno consistente nell'uccisione di un soggetto per eludere il pericolo, incombente su di sé o su altri, di lesioni personali non compromettenti il bene vita o, ancora, un pregiudizio all'integrità fisica arrecato per evitare un vulnus all'onore o alla reputazione). Ne consegue che, se lo stato di necessità ex art. 2045 c.c. si applica nei soli casi in cui il comportamento del pericolante è penalmente giustificato (mentre quello penalmente scusato comporta il risarcimento del danno), non si vede quale rilevanza, ai fini dell'integrazione della relativa fattispecie, possa avere il criterio di proporzionalità menzionato nell'art. 54 c.p.; il rapporto tra fatto e pericolo, infatti, nell'àmbito civilistico è intrinsecamente proporzionato, poiché tramite l'obbligo di pagare l'indennità si compensa il danno arrecato ad un bene di rilevanza minore od eguale rispetto a quello salvaguardato. ${ }^{77}$

\section{II soccorso necessitato}

Lo stato di necessità può indurre a respingere un pericolo incombente su di sé o su altri; in questo secondo caso, com'è noto, si versa in un'ipotesi di soccorso necessitato, ${ }^{78}$ che non presenta particolari requisiti di natura soggettiva, ${ }^{79}$ essendo sufficiente che chi lo effettua sia capace di intendere e di volere, mentre non è richiesto il mancato dissenso del destinatario, per cui il soccorritore può avvalersi dell'art. 2045 c.c. anche nell'ipotesi in cui chi versa in pericolo manifesti una volontà contraria alla salvaguardia della propria persona (PIRAS, 1948, p. 46-48). ${ }^{80}$

${ }^{74}$ Tale distinzione è positivamente codificata nell'ordinamento tedesco, ai §§ 34 (rechtfertigender Notstand) e 35 (entschuldigender Notstand) dello St.G.B., in base ai quali chi agisce in stato di necessità, nel primo caso «handelt nicht rechtswidrig», mentre nel secondo caso "handelt ohne Schuld". A questo proposito rinvio a F. Viganò (2000, p. 362-474) per lo stato di necessità giustificante, nonché pp. 551-601 per lo stato di necessità scusante; la relativa tesi (sulla quale si veda la valutazione di E. Mezzetti (2000, p. 290-292), opta peraltro per un approccio esclusivamente scusante con riguardo all'efficacia esimente dello stato di necessità.

75 In tal caso si discorre di stato di necessità scusante o cogente, riconducibile ad ipotesi codificate di inesigibilità della condotta conforme al precetto come causa di esclusione della colpevolezza, che si rinviene nelle ipotesi in cui un soggetto respinge mediante il fatto necessitato il pericolo incombente su di sé o nei confronti di un prossimo congiunto (mentre il soccorso di necessità sarebbe inquadrabile esclusivamente come causa di giustificazione; cfr. G. Fiandaca-E. Musco, 2014, p. 428).

76 Per una diversa opinione si veda A. Diurni, (2003, p. 100), secondo la quale l'art. 2045 c.c. può applicarsi senza ricorso all'analogia allo stato di necessità scusante, ciò che sarebbe consentito per la duttilità dello strumento indennitario con cui si rimette all'equo apprezzamento del giudice la misura della riparazione. Mi pare peraltro che la coerenza con il sistema delle scusanti penalistiche non possa esimere dal ricorso all'art. 2043 c.c. e dall'integrale applicazione della relativa disciplina.

77 Gli esempi che si è soliti proporre (minaccia al diritto morale d'autore e danno alla vita o all'integrità fisica; si veda M. Briguglio (1963, p. 104) sono a mio avviso inconferenti, in quanto, anzitutto, non considerano adeguatamente il requisito della gravità e, inoltre, muovono da una concezione parcellizzata e non globale della persona(lità). Seppure, difatti, un attributo della personalità venga leso in maniera intensa, ciò non significa che detta lesione si risolva in un danno grave alla persona unitariamente configurata. Ritiene, invero alquanto apoditticamente, che la lesione del diritto morale d'autore integri un danno grave alla persona S. Rossi (2012, p. 708, nota 12), richiamando la conforme opinione di G. Giacobbe (2000, p. 78 ), e di B. Troisi (1984, p. 12). Più articolata la giustificazione di M. Briguglio (1963, p. 24-26). Alcuni spunti sul tema si possono rivenire, in una prospettiva speculare, anche dalla lettura di H. Schack (2005, p. 511-521, in part. p. 516-518).

78 Nella dottrina penalistica l'esenzione da pena nel soccorso necessitato si spiega nella prospettiva del bilanciamento di interessi; così G. Fiandaca-E. Musco (2014, p. 317-318).

79 Per quanto invece attiene ai presupposti di applicabilità, devono riferirsi al soccorritore la non volontarietà della causa del pericolo e l'inevitabilità del danno, mentre vanno valutati con riguardo al soggetto soccorso l'attualità e la gravità del pericolo; in questo senso A. Diurni (2003, p. 191-196).

80 Così anche P. D'Amico (1981, p. 62-69), il quale risolve il problema valorizzando quanto contenuto nell'art. 2031, co. $2^{\circ}$, c.c. in tema di gestione di affari altrui, là dove si afferma che gli obblighi dell'interessato nei confronti del gestore non sorgono con riferimento agli atti di gestione verso i quali il primo abbia manifestato il proprio divieto, ad eccezione dei casi in cui il suddetto divieto sia contrario alla legge, all'ordine pubblico o al buon costume; ne consegue che, stante il valore indisponibile della vita e dell'integrità fisica, l'opposizione del gerito sarà lecita nei soli casi in cui il pericolo sia agevolmente superabile, restando altrimenti priva di effetto la prohibitio domini. In senso contrario B. Troisi (1984, p. $31 \mathrm{~s}$.), che, pur non ritenendo necessaria l'autorizzazione al soccorso da parte del soggetto pericolante, considera preclusiva una volontà contraria di questi, stante la normale disponibilità dei beni attinenti alla c.d. personalità morale (sul presupposto, invero non condivisibile, dell'attinenza del c.d. soccorso necessitato in senso proprio al solo àmbito anzidetto, e vedi infra quanto verrà successivamente osservato sul punto alla nota 102). A. Diurni (2003, p. 198-201), affrontando l'ipotesi dell'aspirante suicida che rifiuti il soccorso, fa opportunamente notare come nel caso di pericolo per la vita o l'integrità fisica la prohibitio domini sia irrilevante, poiché la salvezza dell'individuo costituisce l'adempimento della gestione di affari altrui nell'interesse pubblico. 
Ora, il soccorso necessitato in senso ampio è articolabile essenzialmente in due fattispecie: il dovere di soccorso (legale o negoziale) ${ }^{81}$ ed il soccorso di necessità. ${ }^{82}$ Quanto al primo, ${ }^{83}$ esso deriva direttamente dall'art. 593 c.p., in relazione al quale, per ciò che qui rileva, commette reato chi non presta soccorso a una persona che sia o sembri inanimata o che sia ferita o altrimenti in pericolo; ne consegue che il comportamento rispettoso della norma, seppure cagioni ad altri un danno, deve ritenersi scriminato ex art. 51 c.p., essendo stato compiuto nell'adempimento di un dovere, e, sotto il profilo civilistico, esso va esente da responsabilità e da obblighi di indennizzo (TROISI, 1984, p. 28). Merita osservare a questo proposito che, secondo talune opinioni, l'omissione di soccorso resta preclusa, e il soccorso perde la caratteristica di condotta doverosa, qualora l'intervento esponga il soccorritore ad un rischio personale o nel caso in cui questi si attivi per proteggere "beni" proprî diversi dalla vita e dall'incolumità individuale, versandosi, in tal caso, in uno stato di necessità. ${ }^{84}$ Sulla base di questa prospettiva, chi omettesse il dovere di soccorso sarebbe chiamato a corrispondere un'indennità al soggetto in pericolo ai sensi dell'art. 2045 c.c. Ciò, peraltro, legittimerebbe la paradossale conseguenza di costringere l'omittente a riparare in modo integrale i pregiudizî arrecati nel caso in cui, invece, egli si attivasse nonostante il pericolo per se stesso; infatti, qualora un altro soggetto gli prestasse aiuto arrecando così danno ad altre persone, atteso che questo danno sarebbe conseguenza del comportamento colposo del primo soccorritore (colposo in quanto si sarebbe potuto evitare, mediante l'omissione di soccorso necessitata, di cagionare un pericolo a sé), questi dovrebbe risarcire i danni prodotti dal secondo soccorritore a terzi per la sua salvezza. A mio avviso, allora, non si versa in una situazione di stato di necessità, anche perché chi omettesse di soccorrere non sarebbe minacciato dal pericolo attuale di un danno grave alla persona, poiché il suddetto pericolo sarebbe originato proprio dall'azione ausiliatrice; nessuna conseguenza, risarcitoria o indennitaria, sarebbe da ricollegare all'omittente, che è giustificato in virtù dell'esercizio di un proprio diritto a conservare la vita e l'integrità fisica ex art. 51 c.p., non potendo egli essere vincolato da doveri legali che pregiudichino un siffatto diritto (come emerge sotto il profilo sistematico, seppure ad altro riguardo, dall'art. 5 c.c. in tema di divieto degli atti di disposizione del proprio corpo che cagionino una diminuzione permanente dell'integrità fisica).

Qualora, poi, mediante contratto si costituisca un vero e proprio obbligo di salvataggio nei confronti dell'altro contraente, ${ }^{85}$ i danni prodotti dal relativo comportamento soggiacciono anch'essi alla disciplina dell'art. 51 c.p. sopra illustrata, in quanto il dovere di soccorso rilevante per invocare questa norma è tipizzato non solo dal riferimento all'art. 593 c.p., ma anche dalle posizioni di garanzia che ineriscono a rapporti legalmente o contrattualmente disciplinati, posizioni da coordinarsi necessariamente con l'art. 40, co. $2^{\circ}$, c. p. Deve allora chiarirsi se, nonostante il necessitato, che cagiona danni a terzi nel salvataggio di taluno ${ }^{86}$ possa invocare l'adempimento del dovere per andare esente da qualsiasi obbligo compensativo (risarcitorio o indennitario), il danneggiato sia legittimato ad agire nei confronti del soggetto salvato nei limiti dell'indennità ex art. 2045 c.c., in quanto è quest'ultimo a versare in stato di necessità. ${ }^{87}$ In effetti, trattandosi di soccorso doveroso (legale o negoziale), le conseguenze del comportamento necessitato ricadono esclusivamente a carico del salvato, poiché questi si è giovato dell'aiuto altrui e, pertanto, sarà tenuto a corrispondere l'indennità ex art. 2045 c.c. conformemente alla ratio di tale norma; va invece

81 Spunti di notevole interesse si rinvengono sul tema, in una prospettiva di analisi economica, nelle pur brevi considerazioni di P. H. Rubin (1986, p. 273-276).

82 Cfr. A. Diurni (2003, p. 196-201), la quale, sul presupposto, in parte condivisibile, delle nette similitudini di fondamento, ratio ed effetti del dovere di soccorso e dello stato di necessità, giunge ad argomentate soluzioni che sotto taluni aspetti si discostano dalla prospettiva qui accolta nel testo. Sul quale si veda P. D’Amico (1981, p. 84-102).

84 Così S. Rossi (2012, p. 713).

85 Cfr. sul punto P. D'Amico (1981, p. 113-125), il quale, peraltro, intende il soccorso contrattuale come una fattispecie intermedia tra il soccorso spontaneo e il soccorso obbligatorio; con riguardo ai contenuti della prestazione del soccorritore che si sostanzia nella tutela dell'individuo, si veda in particolare S. Ciccarello (1988, p. 55-61).

86 Cfr. sul tema l'indagine comparatistica di H.-J. Michallek (1995), particolarmente incentrata sul confronto tra il sistema tedesco e quello angloamericano, dalla quale emerge che nel diritto tedesco il danno derivante dal soccorso è oggetto di risarcimento nelle forme dell'assicurazione contro gli infortuni secondo la normativa in tema di previdenza sociale, sì che le pretese risarcitorie di carattere privatistico conservano significato solo per il ricorso del titolare dell'assicurazione e con riferimento alle situazioni di necessità meno rilevanti, le quali non possono formare oggetto delle pretese risarcitorie aventi carattere previdenziale; per contro, nel diritto angloamericano è il risarcimento del danno da fatto illecito delittuale a rivestire il maggiore rilievo (si v. in part. p. 179).

87 Quanto esposto si fonda, ovviamente, sul presupposto che l'accordo contrattuale nulla preveda in merito. 
respinta ogni eventuale pretesa del danneggiato rivolta al soccorritore che, nell'adempiere al suo dovere ex art. 593 c.p. o in base ad un contratto, leda posizioni giuridiche di terzi incolpevoli. ${ }^{88}$

II soccorso di necessità extracontrattuale, correlato al principio costituzionale di solidarietà ex art. 2 Cost., secondo taluni opera invece in modo tale che solo quanti si trovano in una posizione di garanzia nei confronti di un soggetto in pericolo, se arrecano danni nell'azione di salvataggio, potrebbero avvalersi dell'art. 2045 c.c., mentre, in assenza di tale posizione, il soccorritore si esporrebbe al rischio di una responsabilità ordinaria per il fatto commesso. ${ }^{89}$ Invero, se si tiene conto della circostanza che chi si trova in una posizione di garanzia adempie ad un dovere giuridico, quale è proprio quello di attivarsi con riguardo al soggetto in pericolo, in tale caso si è al di fuori dello stato di necessità ${ }^{90}$ e si integra il dovere di soccorso di cui si è detto, con la conseguenza della irresponsabilità (e dell'assenza di obbligazioni indennitarie ${ }^{91}$ ). Allora, mentre per l'applicazione dell'art. 2045 c.c. ai danni causati dall'intervento di soccorso è senz'altro da valorizzare il riferimento all'art. 2 Cost., non è invece necessario ricostruire una posizione di garanzia affinché si integri lo stato di necessità privatistico ${ }^{92}$ In quest'ultima evenienza, peraltro, si pone il problema della possibilità per il soccorritore tenuto al pagamento dell'indennità di pretendere dal salvato il rimborso della somma prestata; ${ }^{93}$ quanto al fondamento del relativo obbligo, le opzioni sarebbero l'applicazione analogica dell'art. 2031 c.c. in materia di gestione di affari altrui ${ }^{94}$ o, con minore efficacia persuasiva, della disciplina del mandato (tacito), con l'obbligo del mandante di tenere indenne il mandatario per le spese sostenute e le obbligazioni assunte nell'adempimento dell'incarico (art. 1720 , co. $2^{\circ}$, c.c.). ${ }^{95}$

\section{L'indennità come effetto della fattispecie ex art. 2045 c.c.}

Tra gli effetti prodotti dallo stato di necessità privatistico rientra senz'altro l'obbligazione indennitaria, la quale deriva direttamente dall'art. 2045 c.c. Infatti la relativa fattispecie è fonte ex lege del rapporto tra

88 Per quanto concerne il problema dei limiti che il soccorritore incontra nel sacrificio dei diritti spettanti a terzi, si ritiene che, mentre per salvare taluno possono arrecarsi pregiudizî di carattere patrimoniale, non sarebbe possibile ledere diritti altrui di natura personale, se non per salvaguardare soggetti nei confronti dei quali ci si trova in una situazione particolare (B. Troisi, 1984, p. 48), seguito da M. Comporti (2002, p. 46). Si veda a tale proposito anche quanto qui indicato nelle seguenti due note.

89 M. Franzoni (2010, p. 1159), ove si propone l'esempio del genitore che interviene per salvare il proprio figlio, al quale sarebbe allora applicabile l'esimente in discorso. Per la sussistenza di una posizione di garanzia nel rapporto genitore-figlio, sancita dal combinato disposto degli artt. 30 Cost., 147 c.c., 577 e 40 , comma $2^{\circ}$, c.p., si esprime B. Troisi (1984, p. 31), al quale si deve la teorica della posizione di garanzia, intesa come ruolo sociale del soggetto agente verso uno degli interessi entrati in collisione (in base alle disposizioni richiamate, peraltro, si nota chiaramente come, piuttosto che ad un ruolo sociale, la suddetta posizione di garanzia si caratterizzi in senso proprio e corrisponda ad un ruolo giuridico).

90 In esso invece si rientrerebbe, secondo l'esempio esposto nella nota precedente, se il genitore salvasse il figlio maggiorenne, nei confronti del quale non sussiste a suo carico una posizione di garanzia, per cui egli sarebbe senz'altro tenuto a corrispondere un'indennità a favore del soggetto danneggiato, versandosi in un'ipotesi di soccorso di necessità in senso proprio e non di un dovere di soccorso.

91 Diversamente, P. G. Monateri (1998, p. 250-251), secondo il quale è necessario verificare anche in caso di dovere di soccorso se l'agente abbia rispettato le regole di diligenza, prudenza e perizia, violate le quali sarebbe applicabile l'art. 2045 c.c. (il che, a ben vedere, se colpa non vi è, non contraddice affatto l'idea suesposta in base alla quale il soccorso doveroso non produce alcuna obbligazione indennitaria); G. Giacobbe (2000, p. 109), che valorizza la possibile rivalsa del soccorritore doveroso verso il soggetto salvato per l'indennità corrisposta a causa dei danni cagionati per tutelare quest'ultimo; S. Rossi (2012, p. 713), ove si sottolinea come, dal punto di vista del soggetto leso, il carattere doveroso o facoltativo del soccorso non rilevi, essendosi verificate comunque a suo carico conseguenze pregiudizievoli (il che, però, renderebbe contraddittorio lo scopo perseguito dall'ordinamento, che da un lato impone al destinatario del comando la salvezza di un soggetto, mentre, dall'altro lato, fa ricadere sul salvatore le conseguenze patrimoniali dell'atto doveroso).

92 B. Troisi (1984, p. 29), fa notare a questo proposito che, operando il dovere di soccorso nelle ipotesi di pericolo per l'integrità fisica della persona, in base a quanto previsto dall'art. 593 c.p., il soccorso di necessità in senso proprio troverebbe applicazione nelle ipotesi, residue, in cui il pericolo di un danno grave si riferisce ad un bene attinente alla c.d. personalità morale. Tale opinione trova concorde M. Comporti (2002, p. 46). In realtà ciò non è sostenibile, alla luce del fatto che talune ipotesi, chiaramente riconducibili alla fattispecie del soccorso necessitato, concernono la tutela dell'integrità fisica della persona e, argomentando a contrario, qualora il soccorritore non le ponesse in atto, assai difficilmente sarebbe applicabile l'art. 593 c.p. Si pensi, ad esempio, alla casistica del vettore di cortesia che compie una manovra azzardata al fine di salvaguardare l'incolumità del passeggero e, così facendo, danneggia un bene altrui. In tal caso non si verserebbe in un'ipotesi di dovere di soccorso ma, senz'altro, sarebbe invocabile il soccorso di necessità, con la conseguente applicazione dell'art. 2045 c.c.

93 II soccorritore in questo caso, dovrebbe ottenere dal soccorso non solo il rimborso dell'indennità eventualmente prestata per i danni a terzi, ma anche il risarcimento per quelli da lui subiti in occasione del salvataggio. La dottrina francese, a questo proposito, ha ritenuto di individuare la fonte dell'obbligo in capo al soccorso in una tacita "convention d'assistance"; cfr. sul punto A. Sériaux (1999, p. 299-311). In senso critico si veda P. D'Amico (1981, p. 115), secondo il quale l'accordo deve essere effettivo e non ricostruibile in base a presunzioni di volontà dei soggetti coinvolti.

94 Per questa opinione cfr. P. D'Amico (1981, p. 74-84), ove viene tratteggiata un'articolata disamina dei possibili diritti vantati dal soccorritore verso il salvato e connessi alla disciplina di cui all'art. 2031 c.c.

95 Ciò se si ritiene che, obbligandosi il mandatario a compiere atti giuridici nell'interesse del mandante (art. 1703 c.c.), tra gli stessi rientri anche il soccorso di necessità (ma vedi supra, par. 4 nel testo, per la qualifica del comportamento necessitato in termini di atto materiale). Per un'applicazione nel diritto francese in queste ipotesi delle norme sul mandato (art. 2000 Code civil) cfr. A. Sériaux (1999, p. 299-300), il quale fa riferimento alla sentenza della Cour de cassation Civ. 1 1 ${ }^{\text {er }}, 27$ mai 1959, JCP 1959 II 11187. Tuttavia, come si ricava dalle riflessioni di P. D'Amico (1981, p. 79-80), la disciplina del mandato non presenta quel carattere altruistico e solidale che, invece, costituisce il fondamento della gestione di affari altrui. 
soggetto necessitato e terzo danneggiato, ${ }^{96}$ costituendo uno degli altri atti o fatti, diversi dal contratto e dal fatto illecito, idonei a produrre obbligazioni in conformità dell'ordinamento giuridico, secondo quanto prevede l'art. 1173 c.c. (PIRAS, 1948, p. 107; BRIGUGLIO, 1963, p. 154). A tale proposito, proprio il riferimento normativo all'indennità viene valorizzato per individuare la particolare natura giuridica del fatto necessitato; ${ }^{97}$ rinviando ad altra sede per approfondimenti sul tema, ${ }^{98}$ può comunque fin d'ora notarsi che l'analisi di tale effetto del comportamento necessitato ha indotto a differenziarne la struttura rispetto a quella del risarcimento del danno, ${ }^{99}$ là dove, si afferma, il risarcimento sarebbe connesso ad un danno ingiusto, mentre l'indennità si giustificherebbe per un arricchimento che il soggetto obbligato a corrisponderla ha conseguito, sì che alla medesima dovrebbe attribuirsi una funzione compensativa di carattere restitutorio..$^{100}$ Un'indagine sistematica di ampio respiro ha peraltro definito l'indennità come una somma dovuta a titolo di corrispettivo, caratterizzato dal suo contenuto pecuniario e dalla proporzionalità alla prestazione effettuata o al sacrificio subito, in base a criterî individuati dalla legge con riguardo alle varie fattispecie concrete. ${ }^{101}$ Nel determinare il quantum dovuto a séguito del comportamento necessitato, però, atteso l'esclusivo riferimento all'equità, ${ }^{102}$ il giudice dovrebbe tenere conto dei parametri implicitamente ricavabili dall'art.

96 La riconducibilità dell'obbligazione indennitaria ad una fonte legale dà conto dell'applicazione ex officio che il giudice è tenuto ad effettuare con riguardo all'art. 2045 c.c., sulla base del fatto che, come si riconosce in giurisprudenza, la domanda di risarcimento totale del danno comprende implicitamente la richiesta di corresponsione dell'indennità (così Cass., 28 luglio 1966, n. 2087, in Resp. civ. e prev., 1967, pp. 24-26, nonché Cass., 19 agosto 2003, n. 12100, in Rep. Foro it., 2003, Responsabilità civile, n. 176, p. 1919). Ne risulta allora che il danneggiato, il quale richiede l'integrale riparazione, là dove il danneggiante provi che il fatto dannoso fu compiuto in stato di necessità, si vedrà riconoscere dal giudice l'indennità anche in assenza di un'apposita domanda subordinata in tal senso; qualora lo stesso danneggiato, oltre al danneggiante, convenga anche il terzo, dal cui fatto colposo è dipeso il pericolo, per ottenere la condanna in solido di entrambi, il giudice dovrà rigettare la relativa domanda e, accertato il ricorrere dell'illecito extracontrattuale ex 2043 c.c., subordinare, in applicazione analogica dell'art. $2047,2^{\circ}$ co., c.c., il pagamento dell'indennità alla mancata soddisfazione delle pretese risarcitorie del leso ad opera del necessitante.

97 Così L. Mengoni (1951, II, p. 361-368, nota a Cass. 28 aprile 1951, n. 1032); Id. (2011, p. 43-52 (da cui si cita), alle p. 51-52); S. Ciccarello (1971, p. 99-106, alla p. 105), sembra invece ritenere l'individuazione della natura giuridica dell'atto necessitato come prioritaria rispetto all'identificazione della natura giuridica dell'equa indennità, in quanto, se il danneggiante realizzasse un fatto illecito, allora il termine indennità sarebbe un sinonimo di risarcimento, seppure contenuto quantitativamente in considerazione delle particolari circostanze in cui l'agente si è trovato ad operare, mentre qualora si ritenesse sussistente una responsabilità da atto lecito dannoso, allora il termine indennità sarebbe stato utilizzato consapevolmente dal legislatore per differenziare la compensazione equitativa dagli obblighi risarcitorî. Peraltro, mi pare che, per la qualificazione dell'istituto, sia necessario prima considerare il dato positivo, ossia la fattispecie e le sue conseguenze, e solo successivamente ricavare dalla complessiva analisi così compiuta le caratteristiche strutturali dell'atto necessitato. Si veda anche P. Rescigno (1979, p. 133-211, a p. 157), il quale sottolinea che nel linguaggio legislativo non è data la possibilità di istituire una costante connessione tra fatto illecito e risarcimento del danno, da un lato, atto lecito dannoso e indennità, dall'altro lato, in quanto sussistono ipotesi di atto lecito in cui la legge impone il risarcimento del danno, come nella rottura della promessa di matrimonio senza giustificato motivo o per avere dato all'altra parte una fondata causa di recesso (art. $81,1^{\circ}$ e $2^{\circ}$ co., c.c.).

98 Cfr. il mio Profili critici dello stato di necessità nel diritto privato, cit., par. 3.

99 II problema è affrontato in chiave di impatto sul sistema della responsabilità civile da P. Perlingieri (2004, I, p. 1061-1087), il quale, applicando i princìi della proporzionalità e della ragionevolezza, in base alla unitarietà della persona umana rigetta la distinzione tra il risarcimento come conseguenza del fatto illecito e l'indennità connessa all'atto lecito dannoso, sì che i due strumenti non possono essere distinti sotto il profilo dell'entità del danno ma in base ad una valutazione del medesimo formulata secondo un giudizio di valore espresso dall'interprete (si vedano in part. le p. 1067-1071). S. Ciccarello (1971, p. 105), osserva che nell'indennità è normalmente irrilevante il profilo soggettivo dell'illecito, mentre nel risarcimento del danno esso è normalmente rilevante; questa opinione, accolta anche da C. Caricato (2012, p. 52, nota 84) presuppone, peraltro, che entrambi gli strumenti compensativi siano conseguenza di fatti illeciti.

100 I termini del dibattito in materia sono puntualmente ricostruiti da S. Ciccarello (1971, p. 99-100). R. Scognamiglio (1962, p. 594-597, a p. 595), dopo avere evidenziato come la contrapposizione tra risarcimento e indennità sopra descritta non sia legittimata dal diritto positivo, ritiene che l'unica prospettiva da accogliersi sia quella che oppone il risarcimento, come strumento tipico della riparazione del danno ingiusto (e, in quanto tale, rilevante per il diritto) ad ogni altro rimedio, nei confronti della lesione di un interesse protetto, che si risolve pur sempre nella corresponsione di un compenso in denaro. In tal modo, sotto il profilo metodologico, si muove dal dato noto e positivo del risarcimento del danno per approdare, in via residuale, alla nozione di indennità, che mostrerebbe pertanto un carattere negativo. Cfr. anche M. Comporti (2002, p. 32), ove si evidenzia che l'indennizzo equitativo si distingue dal risarcimento per il quantum della liquidazione e per l'impossibilità di una riparazione in forma specifica, e pp. 35-38, in cui, dopo avere enunciato il portato pratico della suddetta distinzione (diversità di prova relativamente alle regole di responsabilità contrattuale ed extracontrattuale; differente termine di prescrizione; inammissibilità del risarcimento in forma specifica; limitazione dell'indennità al valore effettivo ed attuale del bene oggetto del diritto sacrificato, anziché compensazione di tutti i danni immediati e diretti), il quale viene sottoposto ad articolate considerazioni critiche, si afferma che l'asserita diversità generale e concettuale tra indennità e risarcimento non ha un sicuro fondamento di diritto positivo, sicché essa sembra rinvenibile solo quando la legge ammette una forma di riparazione del danno senza che ricorrano gli elementi della fattispecie di responsabilità con l'effetto del risarcimento, e quando tale riparazione avviene solo in via pecuniaria, non corrispondendo all'intera lesione (si v. in part. p. 38).

101 Così S. Ciccarello (1971, p. 103), il quale inoltre precisa che, mentre il risarcimento tende alla reintegrazione del patrimonio del soggetto, l'indennità mira alla reintegrazione del "bene", sia pure per equivalente. Insiste su tale ultimo aspetto anche G. Torregrossa (1964, p. 155), secondo il quale "l'adozione del termine indennità anziché di risarcimento è determinata dalla ricorrenza di motivi di opportunità o di pubblico interesse che sconsigliano l'attribuzione del diritto al risarcimento del danno in forma specifica ed impongono di accordare soltanto quello per equivalente".

102 Cfr. sul ruolo dell'equità nella fattispecie le precisazioni di C. Caricato (2012, p. 44-45), che distingue opportunamente tra indennità equa e indennità equitativamente determinata ai sensi dell'art. 1226 c.c., per cui, ricorrendo nello stato di necessità la prima ipotesi, si chiede al giudice di operare un giudizio di comparazione fra il male minacciato e quello effettivamente arrecato; da tale operazione, il giudice desume la misura dell'indennità, tenendo conto della scelta obbligata compiuta dal necessitato, nonché della situazione di chi ha visto aggredita la propria sfera giuridica. Si veda, inoltre, G. Torregrossa (1964, p. 149-150), ove si afferma che l'equità è solo un criterio di misura dell'indennità, non potendo allora influire sulla relativa natura giuridica. 
2045 c.c. ${ }^{103}$ ossia l'entità del pregiudizio ${ }^{104}$ sofferto dalla vittima, ${ }^{105}$ la proporzione tra la gravità del danno causato e quella del danno evitato, l'entità, l'effettività e l'imminenza del pericolo, nonché il comportamento concreto del danneggiante e del danneggiato (M. FRANZONI, 2010, p. 1167-1168; M. POGLIANI, 1969, p. 91); inoltre, data la lacuna normativa sul punto, sarebbe analogicamente applicabile il criterio di cui all'art. 2047, $2^{\circ}$ co., c.c., che prevede, nella determinazione dell'eventuale indennità dovuta dall'incapace per il danno arrecato a terzi, la considerazione delle condizioni economiche delle parti. ${ }^{106}$

Un profilo di particolare interesse che attiene all'obbligazione indennitaria concerne il nesso con i criterî di collegamento previsti, per le ipotesi risarcitorie, nelle fattispecie inerenti alla c.d. responsabilità indiretta o per fatto altrui. ${ }^{107}$ La natura del vincolo, che graverebbe non solo sul soggetto necessitato ma anche sul proprietario del veicolo (art. 2054 c.c.), sul padrone o committente (art. 2049 c.c.), sul genitore o tutore nonché sul precettore o maestro d'arte (art. 2048 c.c.), ${ }^{108}$ anzitutto, è stata individuata a priori ed

103 Pur se deve escludersi il ricorso a regole rigide che ripugnino al concetto di valutazione equitativa, come opportunamente precisa Cass., Sez. Un., 20 agosto 1962, n. 2603, in Resp. civ. e prev., 1963, p. 231-234. Cfr. anche R. Scognamiglio (1968, p. 656), che raccorda la riparazione del danno sofferto dalla vittima dell'atto necessitato - svincolata da un rigoroso riferimento al pregiudizio in ipotesi risarcibile - soprattutto al contemperamento della tutela del leso con la realizzazione di un giusto equilibrio tra gli interessi delle parti in conflitto. Secondo A. De Cupis (1979, p. 585), la misura dell'indennità sarebbe totalmente svincolata dalla reale entità del danno e dovrebbe fondarsi sulla giustizia del caso, per cui la relativa quantificazione prescinderebbe dalle regole inerenti al risarcimento. Peraltro tale assunto è stato persuasivamente confutato rilevando che l'art. 1226 c.c. è finalizzato ad accertare con la maggiore approssimazione possibile l'entità di un danno di cui non sia possibile fornire la prova nel suo preciso ammontare, per cui la valutazione equitativa si risolve in un giudizio di contemperamento dei varî fattori di probabile incidenza su tale indennità; viceversa, l'equo apprezzamento dell'indennità previsto dall'art. 2045 c.c. costituisce un giudizio di contemperamento dell'interesse del danneggiato, ad ottenere l'integrale ristoro del danno, e (ad esso contrapposto) del danneggiante, ad essere totalmente esonerato dall'obbligo risarcitorio. Cfr. in tal senso C. M. Bianca (2012, p. 674-675, cui adde C. Caricato (2012, p. 55-58), secondo la quale, inoltre, il giudizio che il giudice deve compiere, assimilabile alla discrezionalità tecnica del diritto amministrativo, "comporta esclusivamente una valutazione alla stregua di indici posti dal legislatore, vincolando poi l'operatore del diritto, una volta effettuata una siffatta operazione valutativa, a provvedere nel modo che l'ordinamento contempla per quel caso".

104 Secondo taluni dovrebbe escludersi il danno morale, in virtù di una concezione dell'art. 2059 c.c. che, nel caso di specie, ne valorizza il rapporto con l'art. 185 c.p., per cui, poiché il fatto compiuto in stato di necessità non costituisce un reato, esso non è soggetto alle conseguenze civilistiche per quest'ultimo previste. Tale profilo, escludendo la riparazione per il pregiudizio morale subito, accentua la connessione tra l'operatività della esimente (causa di giustificazione) in discorso e il modello generale della responsabilità per colpa di cui all'art. 2043 c.c. Per un'opinione critica, la quale auspica una diversa soluzione in via giurisprudenziale, cfr. M. Comporti (2002, p. 40, nota 48). Tale auspicio può dirsi compiuto e, pertanto, qualora l'interesse leso pertenga non solo a beni giuridici penalmente tutelati ma anche a interessi di rilevanza costituzionale, per quantificare l'entità del pregiudizio dovrà tenersi conto anche del danno morale subìto dalla vittima; il riferimento è, ovviamente, alla prospettiva nella quale la giurisprudenza si muove a partire da Cass., Sez. Un., 11 novembre 2008, n. 26972, in Foro it., 2009, I, cc. 120-159, con osservazioni bibliografiche (cc. 121-123) e nota di A. Palmieri, La rifondazione del danno non patrimoniale all'insegna della tipicità dell'interesse leso (con qualche attenuazione) e dell'unitarietà (cc. 123-128); di R. Pardolesi-R. Simone, Danno esistenziale (e sistema fragile): «die hard» (cc. 128-134); di G. Ponzanelli, Sezioni unite: il "nuovo statuto» del danno non patrimoniale (cc. 134-138); di E. Navarretta, II valore della persona nei diritti inviolabili e la sostanza dei danni non patrimoniali (cc. 139-146). Il problema del danno morale come criterio di quantificazione dell'indennità non si pone, invece, nel caso di stato di necessità avente esclusiva matrice civilistica, atteso che, nelle relative ipotesi, non vi sono, per l'appunto, beni giuridici penalmente tutelati o di rilievo costituzionale (nell'ottica dell'art. 2 Cost.) la cui lesione possa comportare pregiudizî non patrimoniali risarcibili.

105 Cfr. peraltro R. Scognamiglio (1962, p. 596), ove si afferma che, seppure l'entità del danno eserciterà una sensibile influenza sull'equo apprezzamento del giudice, se non altro nel senso di costituire un limite massimo all'indennizzo, essa comunque permarrà al livello di una suggestione di mero fatto di fronte alla asserita libertà di valutazione del danno nei confini dell'equo. A. Venchiarutti (1988, p. 491-492), fa opportunamente notare come, in caso di lesioni all'integrità psico-fisica della persona, il criterio generale in base al quale si esclude l'assoluta equivalenza tra danno subito ed indennità da corrispondere debba recedere, a favore del ripristino per il soggetto leso delle sue potenzialità individuali. In tal senso, mi pare, anche G. Torregrossa (1964, p. 135-136), secondo il quale "l'atto necessitato genera l'obbligo del pagamento dell'indennità che, nel caso della morte di un uomo e quale che sia l'estensione dei poteri equitativi accordati al giudice dall'art. 2045 cod. civ., non può certo assumere ammontare esiguo".

106 M. Franzoni (2010, p. 1168) motiva l'applicazione dell'art. 2047, $2^{\circ}$ co., c.c., se ho ben colto, in base al fatto che l'indennità deve essere determinata ricorrendo a parametri equitativi sia in questa previsione che con riguardo all'art. 2045 c.c. Ciò è condivisibile ma richiede, come si è proposto nel testo, l'ulteriore passaggio argomentativo della lacuna disciplinare come presupposto dell'estensione analogica. Sull'operatività di un siffatto criterio si veda C. Caricato, Danno e indennità, cit., p. 63, per la quale essa si articola in varie direzioni: «da un lato, assunto come dato di partenza il danno effettivamente subito, nel senso di comportare la riduzione della somma determinata, qualora il responsabile versi in condizioni economiche non floride; nel senso di non discostarsi di molto dall'entità che sarebbe liquidata a titolo di risarcimento ove non ricorressero le rilevate circostanze peculiari, qualora l'agente necessitato sia abbiente; ancora, nel senso di comportare una sorta di compensazione dei costi, quando le rispettive situazioni siano di pari livello». Secondo R. Scognamiglio (1962, p. 656), peraltro, esso avrebbe carattere meramente eventuale.

107 Cfr. sul punto A. Corradini (1962, p. 335-339), per una disamina delle ipotesi di responsabilità vicaria, che conduce ad escludere le medesime dall'àmbito di applicazione dell'art. 2045 c.c. Si veda, inoltre, l'inquadramento sistematico di R. Scognamiglio (1968, p. 691-700), secondo il quale, in base alla ratio della suddetta responsabilità, ricorrendo la relazione intersoggettiva valorizzata dalla legge, essa ricomprenderebbe ogni ipotesi in cui altri risponde per danni (p. 693).

108 C. M. Bianca (2012, p. 674) ritiene che l'indennità sia dovuta dai vicarî, anche qualora i medesimi forniscano le prove liberatorie consentite dalle relative previsioni di responsabilità (quindi, anche dai genitori e sorveglianti, pur se provino di non avere potuto impedire il fatto, dai preponenti e dai proprietarî dell'autoveicolo, pur se provino che la circolazione è avvenuta contro la loro volontà). Secondo G. Giacobbe (2000, p. 92 s.), l'estensione dell'obbligo di indennizzo nei casi di soggetto incapace ex art. 2048 c.c. si rende necessaria al fine di evitare "una discriminazione tra colui che, nella situazione di necessità, subisce un pregiudizio causato da un soggetto che risponde direttamente, e colui al quale, invece, il danno viene arrecato da chi è sottoposto alla sorveglianza di un terzo, che ne risponde civilmente". 
utilizzata per avvalorare la tesi del fatto necessitato come speciale illecito civile; ${ }^{109}$ ritengo, invece, che sia necessario risolvere preliminarmente il problema qualificatorio, per cui solo all'esito della relativa analisi si potrà affermare o negare l'estensione della responsabilità vicaria anche alla corresponsione dell'indennità. In tal senso, se l'obbligo di rispondere per un fatto altrui ha come suo necessario presupposto un fatto illecito ai sensi dell'art. 2043 c.c., il danno ingiusto colposamente arrecato dovrà essere risarcito anche dal soggetto determinato in base al proprio rapporto legalmente qualificato con il danneggiante (POGLIANI, 1969, p. 214-215). Ne consegue che, qualora non si ravvisi un illecito nel comportamento necessitato, ${ }^{110}$ sarà tenuto all'indennità il solo danneggiante, mentre per le figure sopra menzionate la relativa obbligazione non verrà ad esistenza (POGLIANI, 1969, p. 89-90). ${ }^{111}$

L'indennità, intesa come un minus rispetto all'obbligazione risarcitoria, ${ }^{112}$ in una prospettiva di efficienza si giustifica anche con riguardo all'opportunità di incoraggiare chi si trovi nell'alternativa di intervenire o meno in ausilio dei terzi sui quali incomba un pericolo imminente (e non altrimenti evitabile in assenza di quell'intervento), poiché tale incentivo non sarebbe efficace senza una norma che garantisca ai soccorritori di non essere tenuti al risarcimento, ma solo a corrispondere, per l'appunto, un'equa indennità per i danni provocati. ${ }^{113}$ L'art. 2045 c.c., allora, può spiegarsi anche per la finalità di incoraggiare i consociati

109 È allora prossima ad un'inversione logica la prospettiva di M. Franzoni (2010, p. 1168), ove si ritiene fondata la tesi che concepisce lo stato di necessità come una figura tipica di responsabilità proprio in base alla, indimostrata, responsabilità solidale dei soggetti civilmente tenuti per il fatto illecito del necessitato. Invece, si ribadisce, è necessario dimostrare che lo stato di necessità integra una forma peculiare di illecito, se si vuole ricavarne le conseguenze in termini di disciplina applicabile (quindi, gli artt. 2048, 2049, 2054, c.c.).

110 In particolare, e sotto il profilo soggettivo, l'applicazione dell'art. 2045 c.c. può verificarsi esclusivamente in assenza di colpa, come ha messo in luce la giurisprudenza; cfr. Cass., 28 febbraio 1953, n. 502, in Resp. civ. e prev., 1953, pp. 351-355, secondo la quale la disciplina dello stato di necessità presuppone che l'autore del fatto dannoso abbia agito senza colpa (pur se la pronuncia in esame riconduce l'atto necessitato alla c.d. responsabilità moderata o attenuata, sulla quale vedi il mio Profili critici dello stato di necessità nel diritto privato, cit., par. 3).

111 Conforme Trib. Varese, 28 febbraio 1955, in Riv. dir. civ., 1957, II, p. 445 (massima), con nota critica di M. Briguglio (1957, p. 445-452); contra App. Milano, 22 febbraio 1957, in Mon. Trib., 1957, pp. 578-581, con nota informativa che sposa la qualifica dello stato di necessità come responsabilità attenuata (p. 581). Cfr. inoltre D. Barbero (1960, I, p. 572-592), il quale, specifica come l'art. 2045 c.c., in quanto rientrante tra le esenzioni insieme agli artt. 2044, 2046 e 2047 , co. $2^{\circ}$., c.c., si sottragga alla distinzione tra norme di nascita e norme di propagazione della responsabilità per fatto illecito, la quale distinzione concerne tutte le previsioni codicistiche dall'art. 2043 c.c. all'art. 2059 c.c. Ciò premesso, le previsioni di cui agli artt. 2054 (co. $3^{\circ}$ ), 2049 e 2048 c.c. sono ascritte al novero delle norme di propagazione (si vedano rispettivamente le pp. 585, 587 e 581 ) e per il relativo operare si richiede l'integrazione di un fatto illecito suscettibile, per l'appunto, di venire da esse propagato (significative le considerazioni svolte in merito all'art. 2049 c.c. per confutarne la ratio secondo la teoria del rischio di impresa, in base alle quali sarebbe contrario alla struttura della norma una responsabilità, che derivasse dal suddetto rischio, del padrone e del committente per il fatto non colposo del dipendente; $p$. 589). A differenti conclusioni giunge M. Briguglio (1957, p. 68-79), secondo il quale l'art. 2049 c.c. si applicherebbe per tutte le ipotesi in cui il dipendente ponga in essere un fatto dannoso da cui derivi una qualsivoglia responsabilità patrimoniale nell'esercizio delle incombenze a lui affidate (in part. v. p. 77).

112 Si veda Cass., Sez. Un, 20 agosto 1962, n. 2603, cit., ove si sancisce espressamente che l'obbligo di corrispondere l'equa indennità ex art. 2045 c.c. costituisce per l'appunto un minus rispetto all'obbligo di risarcire integralmente il danno di cui all'art. 2043 c.c. (in tal senso anche Cass., 15 giugno 1965, n. 1224, in Resp. civ. e prev., 1965, p. 448-449). In dottrina cfr. G. Gentile (1953, p. 314-316, osservazioni a Cass., Sez. Un., 21 febbraio 1953, n. 427, ivi, p. 314-320), il quale, richiamando quanto previsto in tema di concorso di colpa, ne traspone il criterio di quantificazione del danno alla materia in oggetto, ove ravvisa un concorso di fattori non colposi, e propone pertanto di determinare il valore dell'indennità nella metà del quantum risarcitorio (p. 316). Lo stesso autore, in Id. (1970, p. 5-6), si dichiara consapevole del fatto che la soluzione del dimidium appare «grossolana e salomonica, in contrasto con quella elasticità di contenuto e di movimenti che è connaturale ad un istituto del genere», ma sottolinea come sia comunque necessario «offrire nell'assoluto silenzio della legge un minimo di orientamento, salvo i necessari adattamenti nei singoli casi» (p. 6). Su questa proposta si veda la critica di C. Caricato (2012, p. 61, nota 111), la quale ritiene che essa costringa il danneggiato, vittima innocente, a sopportare una ingiusta lesione di un proprio interesse e, in maniera praticamente matematica, anche una parte del costo del danno (tale ultimo rilievo, peraltro, si risolve sulla base del fatto che la stessa tesi criticata parla esplicitamente della necessità di adattamenti nei singoli casi). Secondo D. De Strobel (1965, p. 341, nota 7), tale soluzione merita un più adeguato esame, senza essere frettolosamente accantonata (così, invece, M. Briguglio, 1963, p. 170), che considera senza alcun fondamento la proposta di ricorrere analogicamente alla disciplina del concorso di colpe). Il punto in effetti esigerebbe di essere rimeditato alla luce dell'art. 1227 c.c.; un utile modello argomentativo può rivenirsi nel lavoro di D. Farace (2015, p. 158-180, spec. pp. 177-178), ove, nella prospettiva dei fatti giuridici impeditivi, si propone di considerare unitariamente il fenomeno, collocando cioè sul piano della fattispecie tutte le condotte poste in essere dal complesso dei soggetti interessati, e verificare gli effetti a ciascuno applicabili. In senso diverso si esprime G. Torregrossa (1964, p. 150-151), secondo il quale, attraverso l'applicazione delle regole di equità in funzione dell'ampliamento dell'àmbito di protezione assicurato dall'ordinamento al patrimonio di un soggetto, l'indennità potrebbe anche assumere un ammontare superiore al risarcimento. Per un'articolata confutazione di tale tesi rinvio a C. Caricato (2012, p. 62 , nota 113), la quale, tra le varie censure, sottolinea persuasivamente come un'indennità superiore al risarcimento porterebbe ad arricchire indebitamente il danneggiato e a configurare la misura in esame quasi in termini sanzionatorî, il che sarebbe privo di senso. Cfr. inoltre P. Rescigno (1979, p. 157), ove si chiarisce che la formula dell'indennizzo o indennità, che la legge generalmente preferisce quando la responsabilità patrimoniale discende da un atto lecito, non in ogni caso differisce dal risarcimento del danno per quanto concerne la misura della riparazione, comprensiva delle perdite sofferte e dei guadagni mancati (ai sensi degli artt. 1223 e 2056 c.c.).

113 Cfr. R. Sacco (1959, p. 190-192, spec. p. 191), ove, con riferimento alla ipotetica applicazione pura e semplice del principio che stabilisce il rimborso del lucro conseguito e del danno evitato, si afferma perspicuamente, per sottolinearne i risultati assurdi, che "[...] la norma savia deve incoraggiare l'agente a liberare sé ed altri da pericolo secondo una giusta regola di proporzione fra il male che si mira ad evitare, ed il male che si arreca ad altri. Una regola che condannasse l'agente a sborsare una somma pari al danno patrimoniale evitato, e a corrispondere una mera indennità equa pel danno patrimoniale arrecato ad altri, invoglierebbe l'agente al comportamento necessitato in modo tanto più efficace quanto più fosse lieve il male da sventare, e grande il danno arrecato ad altri". 
a fronteggiare un rischio (in talune ipotesi assai grave), così adempiendo un dovere di solidarietà sociale; ${ }^{114}$ in tal modo verrebbe scongiurata l'indifferenza dei singoli verso i mali altrui e la riduttiva considerazione in termini di pure e semplici liberalità degli eventuali atti di soccorso spontaneamente compiuti (PIRAS, 1948, p. 100).

\section{Lo stato di necessità e l'inadempimento dell'obbligazione}

L'esigenza di estendere la disciplina dell'art. 2045 c.c. alle ipotesi in cui la prestazione è mancata o è stata inesattamente eseguita per salvare sé od altri dal pericolo attuale di un danno grave alla persona si è posta, come problema sistematico, al fine di consentire al debitore necessitato, chiamato a rispondere per l'inadempimento dell'obbligazione, di contenere le conseguenze riparatorie verso il creditore nei confini dell'indennità equitativamente determinata dal giudice. Sul punto si contrappongono tesi che sposano l'indirizzo negativo, più che per argomentazioni di carattere topografico (quindi, in base alla collocazione dell'art. 2045 nel Titolo IX “Dei fatti illeciti” anziché nel Titolo I "Delle obbligazioni in generale" del Libro IV del codice civile ${ }^{115}$ ), in virtù di una concezione dell'art. 1218 c.c. come disciplina esaustiva dell'inadempimento e della relativa responsabilità, ${ }^{116}$ e proposte positive, in cui si esalta la circostanza che la ratio dell'art. 2045 c.c. ricorre identica nella materia contrattuale, ${ }^{117}$ oppure si evidenzia il valore superiore della persona rispetto al vincolo obbligatorio, avente natura patrimoniale, da ciò ricavando l'articolazione dei criterî di imputazione della responsabilità, che non sarebbero deducibili esclusivamente dal citato art. 1218 c.c. ma che potrebbero individuarsi anche in altre disposizioni (tra cui, per l'appunto, l'art. 2045 c.c.). ${ }^{118} \mathrm{~A}$ questo proposito, un'originale prospettiva sottolinea il nesso tra il pregiudizio arrecato dall'inadempimento all'altrui diritto di credito e la natura di fatto illecito extracontrattuale del comportamento necessitato che lede gli interessi del creditore, qualora fosse stato un terzo a cagionare il pericolo che ha indotto il debitore a non eseguire la prestazione. Si verificherebbe, allora, un concorso tra responsabilità contrattuale del debitore e responsabilità extracontrattuale del terzo; quest'ultimo, in particolare, concorrerebbe con il debitore, anch'egli corresponsabile dell'illecito extracontrattuale in quanto soggetto necessitato. Lo stesso debitore, allora, "può essere condannato al pagamento della indennità poiché il suo comportamento dà luogo ad un fatto illecito eventualmente sotto il profilo del concorso nella lesione del credito" (M. FRANZONI, 2010, p. 1165). Una siffatta opinione, per quanto perspicuamente individui fattispecie concrete ove si riscontra di frequente la sovrapposizione tra inadempimento e fatto illecito, ${ }^{119}$ non appare risolutiva poiché dà conto delle

114 Questa chiave di lettura del fenomeno è stata particolarmente sviluppata dalla dottrina nordamericana; sulla Good Samaritan Intervention Doctrine e sull'incoraggiamento dei Good Samaritan Acts rinvio a H. Dagan (1998-1999, p. 1152-1200).

115 Si veda M. Franzoni (2010, p. 1163-1164), il quale riferisce del mancato valore che per gli interpreti riveste l'argomento sistematico (parlerei, invece, di criterio topografico), come si evince dalle osservazioni di D. Rubino (1970, p. 492), secondo il quale "non può certo essere decisiva la collocazione della norma nel Titolo relativo agli atti illeciti extracontrattuali, che può anche spiegarsi semplicemente vuoi con la sua più frequente applicazione pratica in materia extracontrattuale, che con la sua derivazione dal diritto penale".

116 In quest'ottica si collocano le riflessioni di L. Mengoni (2011, p. 46-50); P. Rescigno (1951, II, p. 388-394); A. Tabet (1951, IV, cc. 193-201). E. Bonvicini (1971, p. 515) esclude invece il rilievo dell'art. 2045 c.c. nel campo contrattuale in base al carattere particolare, di tipica responsabilità oggettiva, della relativa fattispecie.

117 D. Rubino (1970, p. 492), nel rilevare ciò, ritiene ammissibile l'estensione dell'art. 2045 c.c. al settore contrattuale, in virtù, però, di un'interpretazione estensiva piuttosto che dell'analogia, la quale ultima incontrerebbe l'ostacolo derivante dalla natura eccezionale della previsione in discorso.

118 Si distingue per questa prospettiva B. Troisi (1984, p. 88-90). L'argomento è stato ulteriormente sviluppato da questo Autore in Lo stato di necessità nel diritto civile, (ESI) Napoli, 1988, pp. 115-145, spec. pp. 135-142, secondo il quale, poiché l'art. 2045 c.c., il cui schema e la cui ratio ricorrono identici in materia contrattuale, disciplina un'ipotesi specifica di inadempimento, il debitore inadempiente sarà tenuto al pagamento dell'indennità prevista dalla suddetta disposizione così da ripartirsi equamente le conseguenze pregiudizievoli del comportamento necessitato. Cfr., inoltre, M. Franzoni (2010, p. 1163-1166) e, risalentemente, G. Auletta (1948, I, 1, cc. 79-80, nelle osservazioni a Cass., 18 gennaio 1947, n. 44, cc. 79-81. M. Comporti, Fatti illeciti: le responsabilità presunte. Artt. 2044-2048, cit., p. 46-48), ritiene che lo stato di necessità non possa non rilevare come causa di giustificazione dell'inadempimento, pur se il creditore danneggiato potrebbe pretendere l'indennità equitativa ex art. 2045 c.c.; difatti, la regola dello stato di necessità, avente valenza generale, secondo l'autore dovrebbe essere applicata nella sua interezza sia nel settore extracontrattuale sia in quello contrattuale, così da evitare ingiustificate situazioni di diseguaglianza.

Sintetizza questo indirizzo di pensiero, facendo notare come, secondo il medesimo, lo stato di necessità si configuri come una norma di carattere generale il cui àmbito di operatività ricomprenda qualunque condotta necessitata che produca conseguenze dannose (ivi compreso il mancato adempimento di un'obbligazione per la situazione necessitata in cui versava il debitore), S. Rossi (2012, p. 720). Si veda, infine, C. M. Bianca (2012, p. 42-44), secondo il quale la previsione normativa dello stato di necessità, indicando la particolare rilevanza che assume per l'ordinamento la motivazione di chi compie l'atto lesivo al fine di trarne salvezza a favore proprio o di altri, esprime la tolleranza legale dell'atto necessitato, ponendo un principio valevole sia per l'illecito civile che per l'inadempimento.

119 La giurisprudenza in materia riguarda, soprattutto, il contratto di trasporto di persone, con riferimento al quale, oltre al cumulo tra responsabilità contrattuale ed extracontrattuale a favore del trasportato-creditore che subisca lesioni, può senz'altro ritenersi frequente la presenza di un terzo che determini lo stato di necessità del debitore trasportante. Cfr. per questa segnalazione della casistica M. Franzoni (2010, p. 1164). 
sole ipotesi in cui lo stato di necessità non derivi da cause fortuite naturali, ${ }^{120}$ esponendosi, sotto il profilo dell'utilità pratica per il creditore e della persuasività teorica circa l'applicazione alla materia contrattuale dell'art. 2045 c.c., a taluni rilievi critici. Difatti, per il creditore che abbia a disposizione nei confronti del debitore il rimedio risarcitorio e quello indennitario sarà naturale optare per il primo, in quanto maggiormente satisfattivo e, inoltre, proprio il ricorrere al concorso tra illecito aquiliano e responsabilità da inadempimento per giustificare l'applicazione della disciplina sullo stato di necessità comprova come quest'ultima resti confinata nell'àmbito extracontrattuale. ${ }^{121} \mathrm{~A}$ tale conclusione sistematica giunge, persuasivamente, la dottrina che esalta il ruolo dell'art. 1218 c.c., al quale attribuisce, come si è già detto, la funzione di regolare in via esclusiva gli effetti prodotti dalla mancata o inesatta esecuzione della prestazione da parte del debitore. Di conseguenza, lo stato di necessità non libera dall'obbligo di eseguire la prestazione, pur se sullo stesso debitore incombe il pericolo attuale di un danno grave alla persona. Nei rapporti che si delineano tra caso fortuito e situazione necessitata, si chiarisce però come talune fattispecie concrete, alle quali vorrebbe applicarsi lo stato di necessità ${ }^{122}$ per tenere esente l'obbligato dal risarcimento del danno, siano più propriamente ipotesi nelle quali ricorre un caso fortuito, che rende la prestazione impossibile per causa non imputabile al debitore, liberandolo da qualsivoglia responsabilità. Gli esempi consueti riguardano la mancata riconsegna nei termini contrattuali dell'appartamento da parte dell'inquilino che vi giace gravemente infermo, oppure il rifiuto della guida, impegnatasi con un cliente a condurlo attraverso un valico montano, di partire per la méta in quanto giunta a conoscenza che il percorso è reso pericoloso dalla presenza di fuorilegge; per essi si afferma la ricorrenza dello stato di necessità, il quale, però, deve negarsi poiché si tratterebbe di impossibilità sopravvenuta della prestazione, con conseguente esonero del debitore da qualsivoglia responsabilità (tranne, si precisa, l'obbligo di corrispondere l'ingiustificato arricchimento per l'inquilino, ai sensi dell'art. 2041 c.c., e la restituzione della controprestazione eventualmente già ricevuta secondo le norme relative alla ripetizione dell'indebito, ex art. 1463 c.c., per la guida). ${ }^{123}$

Più precisamente, si parla di sopravvenuta impossibilità della prestazione nel momento in cui il pericolo investe la persona del debitore in quanto implicata nel rapporto obbligatorio, ossia qualora il pericolo stesso sia collegato con il contenuto della prestazione, traducendosi in un suo impedimento oggettivo. ${ }^{124}$ Se ne deduce che la nozione positiva di impossibilità non è ristretta agli impedimenti naturalmente invincibili, ma anche a quelli insuscettibili di essere vinti se non con il sacrificio dell'integrità personale o di un altro attributo della personalità dell'agente. ${ }^{125}$

120 Ciò di cui si dichiara consapevole lo stesso M. Franzoni (2010, p. 1165).

121 Nello sviluppo del proprio ragionamento, M. Franzoni (2010, p. 1165), osserva che, concorrendo con il terzo necessitante nell'illecito civile per lesione del credito, «il debitore inadempiente, siccome è in stato di necessità, può essere condannato al pagamento della indennità, poiché il suo comportamento dà luogo ad un fatto illecito eventualmente sotto il profilo del concorso nella lesione del credito». In questo modo, da un lato si presuppone che l'art. 2045 c.c. non si applichi alla materia contrattuale, atteso che l'indennità cui sarebbe tenuto il debitore deriverebbe dal concorso con il terzo e non dalle circostanze in cui si è verificata la mancata o inesatta esecuzione della prestazione, mentre, dall'altro, si ipotizza che il creditore agisca in giudizio per ottenere l'indennità ex art. 2045 c.c. anziché il risarcimento ex art. 1218 c.c. verso il proprio debitore, il che appare difficilmente riscontrabile sotto il profilo della razionalità concreta dell'attore.

122 L. Mengoni (2011, p. 47-48) propone, come ipotesi sicura di stato di necessità in materia contrattuale, il seguente esempio: "Tizio, improvvisamente assalito da Caio, il quale intende ucciderlo per vendetta, offre al suo aggressore, in cambio della vita, la cosa avuta in deposito da Sempronio. Caio accetta, e le circostanze sono tali che il pericolo non era altrimenti evitabile, per es. offrendo una cosa propria. In questa ipotesi, evidentemente, l'azione violenta di Caio (fortuito) è diretta contro Tizio, senza alcun riferimento con la sua qualità di depositario della cosa di Sempronio, sicché non è per niente compromessa la possibilità di conservazione della cosa medesima. Caio si proponeva di uccidere Tizio per vendetta, non di minacciarlo a scopo di rapina, e quindi il comportamento di Tizio, contrario all'obbligazione verso Sempronio (consegna della cosa a Caio), poteva essere evitato". L'Autore chiarisce persuasivamente che, dalla mancata conservazione della cosa avuta in deposito, dovuta non a caso fortuito in senso tecnico, bensì all'attività posta in essere dal debitore per sottrarsi all'azione dannosa del terzo (stato di necessità), deriva certamente l'irresponsabilità penale di Tizio per il reato di appropriazione indebita (art. 646 c.p.), secondo quanto prevede l'art. $54,3^{\circ}$ co., c.p., ma anche la piena responsabilità per i danni in sede contrattuale (ai sensi degli artt. $1218 \mathrm{e}-$ arg. ex -1780 c.c.).

123 In tal senso L. Mengoni (2011, p. 48) e, per esemplificazioni ulteriori, G. Osti (1918, p. 209-259, 313-360, 417-471, spec. pp. 222-224, dove si afferma che "come non sarebbe vincolatrice la promessa di eseguire un trasporto di persone o di cose per vie di comunicazione intercettate da bande armate ostili di cui fosse necessario vincere la resistenza, così dovrebbe ritenersi estinta l'obbligazione del vettore per esserne divenuto impossibile l'oggetto, quando una tal condizione di cose fosse venuta in essere posteriormente al contratto". In questa prospettiva già, risalentemente, (o. N.) Lehmann (1874, p. 237-242); W. Kisch (1900, p. 13); H. Titze (1900, p. 4). Sull'esempio dell'inquilino [che risulta discusso da V. Polacco (1915, 1, p. 368, per l'illustrazione, e p. 371, per la soluzione nei termini del conflitto tra diritto patrimoniale e diritto della persona che vede la prevalenza del second), cfr., in senso diverso dalle conclusioni precedenti, A. Tabet (1951, c. 201), ove si afferma che il ritardo nell'adempimento deve fare capo a quest'ultimo e non al creditore, il quale ha diritto alla puntuale restituzione.

124 L. Mengoni (2011, p. 48), che rileva come la connessione del fortuito con la prestazione, oggettivamente considerata, per escludere le relative ipotesi dallo stato di necessità ed accostarle alla nozione di impossibilità sopravvenuta (così da integrare, allora, la nozione di caso fortuito in senso tecnico), debba essere tale che la prestazione ne risulti negativamente necessitata, quindi che l'impedimento sia assoluto (perciò, insormontabile).

125 Così L. Mengoni (2011, p. 49), riprendendo e puntualizzando il pensiero di G. Osti (1918, p. 223). 
A fronte di ciò, può dirsi che, nell'àmbito del rapporto obbligatorio, una valutazione del caso concreto $^{126}$ che voglia valorizzare impedimenti alla prestazione correlati al pericolo attuale di un danno grave alla persona del debitore deve essere effettuata in base al parametro del dovere di correttezza di cui all'art. 1175 c.c., senza che si debba ricorrere allo stato di necessità ex art. 2045 c.c. ${ }^{127}$ Pur se la riflessione in merito è finalizzata a garantire al creditore almeno un parziale ristoro dei danni subiti a séguito dell'inadempimento, deve considerarsi una rilevante differenza tra le fattispecie extracontrattuali, cui si applica la norma sullo stato di necessità, e quelle relative all'inadempimento del rapporto obbligatorio: nel primo caso il danneggiato, subendo un pregiudizio da un soggetto con il quale non sussisteva una previa relazione giuridicamente disciplinata (o, almeno, in un contesto ove la medesima, se eventualmente presente, non perteneva al fatto dannoso), ha diritto ad una compensazione di tale pregiudizio senza che eventuali reciproci doveri pregressi verso il danneggiante limitino o escludano la suddetta compensazione. Per contro, nel rapporto obbligatorio, qualora la pretesa all'adempimento, in una situazione di grave ed oggettiva difficoltà del debitore non dovuta a sua colpa, contraddica il dovere di correttezza ex art. 1175 c.c., al creditore, proprio perché su di esso incombe il rispetto di tale dovere, nulla sarà dovuto per la mancata soddisfazione del suo interesse.

Allora, se il creditore non riceve la prestazione dovuta in presenza delle circostanze anzidette, o ciò deriva dall'impossibilità, come sopra ricostruita, di eseguire la medesima, così esonerando il debitore, oppure vi sarà inadempimento ai sensi dell'art. 1218 c.c., il che impone all'obbligato di risarcire il creditore: tertium non datur, per cui non sarà ipotizzabile uno stato di necessità che, in applicazione diretta 0 analogica ${ }^{128}$ dell'art. 2045 c.c., attenui il quantum dovuto dal necessitato-debitore a titolo di riparazione, contenendolo nei limiti dell'indennità equitativamente determinata dal giudice. ${ }^{129}$

\section{Conclusioni}

Le riflessioni qui proposte sollecitano a ridiscutere la validità del brocardo latino necessitas non habet legem; difatti, sotto il profilo sistematico, la regolamentazione dello stato di necessità e dei suoi riflessi negli ambiti ordinamentali da esso coinvolti appare assai più articolata di quanto il contenuto degli artt. 54 c.p. e 2045 c.c. possa a prima vista palesare. In particolare, la necessità privatistica, sulla quale si è concentrata l'attenzione, appare irriducibile ad una ratio unitaria che chiarisca l'opzione legale dell'obbligo compensativo

126 Merita sottolineare quanto rileva S. Rossi (2012, p. 720), secondo il quale «si deve comunque ritenere che spetti all'interprete accertare di volta in volta, attraverso un'indagine di fatto sugli elementi costitutivi dell'istituto analizzato, se nel caso concreto la pretesa del contraente, ancorché raggiungibile solo attraverso un comportamento lesivo di un diritto della personalità dell'altra parte, sia esigibile o meno, il che riporta alla competenza dell'interprete il giudizio di bilanciamento degli interessi in gioco e l'eventuale applicazione della fattispecie di cui all'art. 2045 c.c.». Cfr. inoltre in termini generali N. Rizzo (2015, p. 332), che sottolinea come l'operazione di bilanciamento sia strettamente legata alla fattispecie oggetto della decisione, tenuto conto del fatto che la composizione tra diritti o principî e tra gli uni e gli altri, da un lato, ed interessi di carattere istituzionale o generale, dall'altro, possa derivare solo da un esame in concreto e a posteriori delle questioni che pone il divenire quotidiano.

127 Cfr. in tal senso F. D. Busnelli (1964, p. 177-179), il quale esclude l'estensione dell'art. 2045 c.c. alla responsabilità contrattuale proprio sulla base del rilievo che i relativi problemi possono convenientemente affrontarsi mediante l'applicazione dell'art. 1175 c.c. Si veda, inoltre, U. Natoli (1984, p. 107-112), il quale sviluppa il riferimento all'art. 1175 c.c. con particolare riguardo al conflitto tra l'obbligo del debitore di eseguire la prestazione patrimoniale nei confronti del creditore e il dovere di salvezza nei confronti di un terzo, particolarmente qualificato in base al principio di umana solidarietà sancito in termini generalissimi dall'art. 2 Cost; ne consegue che la prestazione suddetta, se non impossibile, sarebbe comunque inesigibile, tanto più che il cennato principio di umana solidarietà estende la sua influenza anche alla posizione del creditore (cfr. spec. pp. 111112).

128 Ritiene l'art. 2045 c.c. non analogicamente applicabile nelle ipotesi di responsabilità contrattuale G. Stolfi (1951, IV, c. 192), argomentando tale conclusione con il rilievo in base al quale non sussiste la lacuna che legittima l'analogia, in quanto vi è una compiuta disciplina dell'inadempimento di obblighi specifici apprestata dall'art. 1218 c.c. In realtà una lacuna sussisterebbe nel momento in cui lo stato di necessità si presenta come causa di inesigibilità della prestazione, sì che le conseguenze risarcitorie vengono meno ma ci si chiede se il creditore abbia almeno il diritto di vedersi corrisposta un'indennità per il danno subito (considerando, ad esempio, che la stessa indennità può pretendersi da chi sfrutta lo stato di necessità per concludere a condizioni inique un contratto rescindibile, ai sensi dell'art. $1447,2^{\circ}$ co., c.c., sì che, a più forte ragione, ad essa dovrebbe in teoria aspirare chi, in virtù di un'obbligazione validamente costituita, esige l'adempimento, poi non verificatosi per le circostanze necessitanti). II ruolo della correttezza ex art. 1175 c.c., come sopra ricostruito, fa propendere per la soluzione negativa.

129 Per questa conclusione si veda F. D. Busnelli (1964, p. 179). Cfr. inoltre P. Perlingieri (1975, p. 463-466), il quale, nel sottolineare come la nozione di impossibilità sopravvenuta subentri quando il diritto e/o il dovere attinenti alla sfera esistenziale del soggetto, che risultano preminenti rispetto agli interessi patrimoniali dedotti in obbligazione, si pongano in contrasto con questi ultimi, osserva che la disciplina di cui agli artt. 1218 , 1256 e 1259 c.c. fa propendere per escludere l'applicabilità in sede di non adempimento dell'obbligazione dell'indennità ex art. 2045 c.c. U. Natoli (1984, p. 112), sottolinea come, pur se il creditore, escludendosi la responsabilità del debitore sulla base delle norme generali che disciplinano l'adempimento, non possa pretendere da questi l'indennità ex art. 2045 c.c. in quanto tale norma sarebbe inapplicabile al relativo rapporto, non si può però escludere in concreto che egli si rivolga a colui che, avendo causato la situazione di pericolo, ha impedito al debitore di adempiere, o che si possano presentare gli estremi per un'eventuale azione di arricchimento ingiustificato ai sensi dell'art. 2041 c.c. 
a carico del necessitato; mi pare, perciò, maggiormente proficuo declinare gli stati di necessità, in senso plurale, così da rinvenire il fondamento dell'autotutela di chi respinge da sé il pericolo attuale di un danno grave alla persona. Anche la natura giuridica del comportamento necessitato, da qualificarsi come atto lecito (non antigiuridico) dannoso, risulta compatibile con la molteplicità (oltre che concreta, anche) tipologica delle situazioni necessitanti, tutte peraltro caratterizzate dall'impedimento all'operare della responsabilità ex art. 2043 c.c. e dalla ricostruzione in termini di giustizia distributiva dell'indennità spettante al soggetto leso.

Sotto il profilo pratico, infine, l'istituto può forse ricevere un rinnovato vigore applicativo se coordinato con la disciplina delle persone giuridiche e degli enti collettivi in generale, fuoriuscendo dalle secche delle ipotesi concernenti la circolazione di autoveicoli e la responsabilità medica, alle quali il giudice civile è solito guardare là dove si tratta di fare applicazione dell'art. 2045 c.c. in via (talvolta) autonoma rispetto alla casistica penale. In particolare, quando si intersechi con la responsabilità amministrativa delle persone giuridiche, l'atto necessitato troverà una propria regola non nella norma penale ma in quella civile, attesa la peculiare natura della suddetta responsabilità che si palesa assai prossima al modello di illecito consegnato all'art. 2043 c.c., sul quale, allora, tale esimente va ad innestarsi.

\section{Riferenze}

AIELLO, C. voce Stato di necessità (diritto penale). In: Enciclopedia giuridica italiana. Roma: Istituto della Enciclopedia Italiana Fondata da Giovanni Treccani, 1993. v. XXX. p. 1-13.

BARBERO, D. Criterio di nascita e criteri di propagazione della responsabilità per fatto illecito. Rivista di diritto civile, Bologna, v. I, p. 572-592, 1960.

BASSENGE, P. sub § 904, in Palandt Bürgerliches Gesetzbuch, München, Verlag C. H. Beck, 2015 (74. neubearbeitete Auflage). p. 1532-1533.

BIANCA, C. M. Diritto civile. La responsabilità. Milano: Giuffré, 2012. v. 5.

BOCCA, C. Lo stato di necessità (art. 2045 c.c.). Resp. civ. e prev., Milano, p. 97-106, 1954.

BUSNELLI, F. D. La lesione del credito da parte di terzi. Milano: Giuffré, 1964.

BONASI BENUCCI, E. Colpa e stato di necessità. Rivista giuridica circ. e trasp., Roma, p. 1129-1134, 1954.

BONVICINI, E. La responsabilità civile. Milano: Giuffré, 1971. t. I.

BRIGUGLIO, M. Stato di necessità e responsabilità indiretta. Rivista di diritto civile, Milano, v. II, p. 445-452, 1957.

BRIGUGLIO, M. Lo stato di necessità nel diritto civile. Padova: CEDAM, 1963.

CANARIS, C. W. Notstand und „Selbstaufopferung“ im Straßenverkehr. Juristenzeitung, 1963.

CANARIS, C. W. Gesammelte Schriften. Berlin: De Gruyter, 2012.

CARICATO, C. Danno e indennità. Torino: Giappichelli, 2012.

CARVALHO FERNANDES, L.; BRANDÃO PROENÇA, J. (Coord.). Comentário ao Código Civil. Parte Geral. Lisboa: Universidade Católica Editora, 2014. p. 801-805.

CASTRONOVO, C. La nuova responsabilità civile. Milano: Giuffré, 2006.

CIANCI, A. G. Diritto privato e libertà costituzionali. Libertà personale. Napoli: Jovene, 2016. v. I.

CICCARELLO, S. voce Indennità (dir. priv.). In: Enc. dir., vol. XXI, Milano: Giuffré, 1971, p. 99-106.

CICCARELLO, S. Dovere di protezione e valore della persona. Milano: Giuffré, 1988.

COMPORTI, M. Esposizione al pericolo e responsabilità civile. Napoli: Morano, 1964. 
COMPORTI, M. Fatti illeciti: le responsabilità presunte. Artt. 2044-2048, In: Il Codice Civile.

Commentario (fondato da P. Schlesinger, diretto da F. D. Busnelli). Milano: Giuffré, 2002. p. 21-50.

CONCAS, L. voce Scriminanti. In: Novíssimo Digesto Italiano. Torino: UTET, 1969. v. XVI. p. 793-809.

CORMìo, B. Stato di necessità e colpa del terzo. Giur. it., Torino, 1962, II, cc. 353-358, nota ad App.

Cagliari, 30 giugno 1961, ivi, cc. 354-360.

CORRADINI, A. Stato di necessità e soggetto responsabile. Dir. proc. amm., Milano, [s.n.t], p. 335-339, 1962.

CORRADO, R. Colpa del terzo e stato di necessità. Riv. dir. comm., Padova, v. II, p. 270-274, 1949, nota a App. Roma, sent. 19 luglio 1948, ivi, p. 270-274.

CORSARO, L. voce Responsabilità civile, I) Diritto civile. In: Enciclopedia giuridica italiana. Roma: Istituto della enciclopedia italiana fondata da Giovanni Treccani, 1976. v. XXVI, p. 1-37.

COSTA, Mário Júlio de Almeida. Direito das Obrigações. 12. ed. Rev. act. Coimbra: Almedina, 2009.

D'AMICO, P. II soccorso privato. Napoli: ESI, 1981.

DAGAN, H. In Defense of the Good Samaritan. Mich. L. Rev., Michigan, v. 97, p. 1152-1200, 1998-1999.

DISTASO, N. Stato di necessità e fatto del terzo. Foro pad., Roma, 1952, I, cc. 1093-1102, nota a Corte d'Appello di Napoli, 24 dicembre 1951, cc. 1094-1103.

DIURNI, A. Gli stati di giustificazione nella responsabilità civile. Torino: Giappichelli, 2003.

DIURNI, A. Notstand und Nothilfe. Eine dogmatische Untersuchung auf der Grundlage des deutschen und italienischen Zivilrechts. Bielefeld: Gieseking, 1998.

DE CUPIS, A. II danno. Teoria generale della responsabilità civile. Milano: Giuffré, 1979. v. 1.

DE LIMA, P.; VARELA, A. Código Civil anotado. 4. Ed. Coimbra: Wolters Kluwer Portugal/Coimbra Editora, 2010. v. 1.

DE STROBEL, D. II fatto dannoso necessitato (con particolare riferimento all'atto necessitato per la condotta colposa di un terzo in incidente stradale). Resp. civ. e prev., Milano, [s.n.t], p. 337-352, 1965.

DE VASCONCELOS, P. P. Teoria Geral do Direito Civil. 6. ed. Coimbra: Almedina, 2010.

ELLENBERGER, J. sub § 228. In: Palandt Bürgerliches Gesetzbuch. München: Verlag C. H. Beck, 2015. p. 252-253. (74. neubearbeitete Auflage).

FARACE, D. Sul concorso colposo dei soggetti lesi. Riv. dir. civ., Milano, p. 158-180, 2015.

FIANDACA, G.; MUSCO, E. Diritto penale. Parte generale. Bologna-Roma: Zanichelli, 2014.

FRANZONI, M. L'illecito. In: FRANZONI, M. Trattato della responsabilità civile. Milano: Giuffré, 2010. v. 1.

GAMBARO-R. SACCO, A. Sistemi giuridici comparati. Torino: UTET, 2008.

GAMBINO, F. II rapporto obbligatorio: de Le Obbligazioni. In: Trattato di diritto civile diretto da Rodolfo Sacco. Torino: UTET, 2015. v. 1.

GENTILE, G. "Indennità" e "stato di necessità". Resp. civ. e prev., Milano, p. 434-435, 1950, nota a Cass., 23 agosto 1950, n. 2531, ivi , p. 434-436.

GENTILE, G. L'indennità moderata per l'atto necessitato. Resp. civ. e prev., Milano, p. 314-316, 1953, osservazioni a Cass., Sez. Un., 21 febbraio 1953, n. 427, ivi, p. 314-320.

GENTILE, G. Questioni vecchie e nuove. Resp. civ. e prev., p. 3-22, 1954.

GENTILE, G. Questioni vecchie e nuove. Resp. civ. e prev., Milano, p. 3-22, 1954.

GERICKE, O. Überblick über die Lehre von der Notwehr und dem Notstande nach dem BGB, nebst einer Kritik der Oetkerschen Reformvorschläge. Berlin: Marschner, 1909. 
GIACOBBE, G. Legittima difesa e stato di necessità nel sistema della responsabilità civile, estratto da Illecito e responsabilità civile. In: Trattato di Diritto Privato da Bessone. Torino, 2000. v. 10. t. I.

GIRARD, B. Responsabilité civile extracontractuelle et droits fondamentaux. Issy-les-Molineaux: LGDJ lextenso éditions, 2015.

GROTHE, H. sub § 228. In: Münchener Kommentar zum Bürgerlichen Gesetzbuch, Band 1, Allgemeiner Teil, 1. Halbband: §§ 1-240 · ProstG, 5. Auflage: München, Verlag C. H. Beck, 2006. p. 25342541.

HOGENSCHURZ, J. Die Entwicklung des Prinzips der Aufopferungshaftung in den zivilrechtlichen Notstandsfällen am Beispiel der Schadensersatzpflicht des § 904 S. 2 BGB, (diss.). Bonn, 1997.

INZITARI, B. voce Necessità (diritto privato). In: Enciclopedia del diritto. Milano, 1977. vol. XXVII, p. 852-866.

JAPOCE, F. Lo stato di necessità nel diritto privato (estratto dalla Enciclopedia Giuridica Italiana, vol. XI, parte I). Milano: Società Editrice Libraria, 1917.

JOLOWICZ, J. A. Grounds of Justification - English Law. In: AA. VV., In memoriam Jean Limpens. Studiedagen aansprakelijkheidsrecht/Journées d'études sur le droit de la responsabilitél Symposium on Civil Liability. Antuérpia: Kluwer, 2000. p. 223-248.

$\mathrm{KISCH}, \mathrm{W}$. Die Wirkungen der nachträglich eintretenden Unmöglichkeit der Erfüllung bei gegenseitigen Verträgen nach dem Bürgerlichen Gesetzbuche für das Deutsche Reich. Jena: Fischer, 1900.

LALLEMENT, P. L'état de nécessité en matière civile (thèse). Paris: Les presses universitaires de France - PUF, 1922.

LANDMANN, V. Notwehr, Notstand und Selbsthilfe im Privatrecht. Zürich: Schulthess, 1975.

LATAGLIATA, A. R. Stato di necessità e risarcimento del danno. Dir. e giur., Roma, [s.n.t], p. 167-172, 1953.

LEHMANN, (O. N.). Über die civilrechtilichen Wirkungen des Nothstandes. In: (Jherings) Jahrbücher für die Dogmatik des heutigen römischen und deutschen Privatrechts, XIII. Band: Jena, Fischer, 1874. p. 237-242.

LIMPENS, J.; KRUITHOF, R. M.; MEINERTZHAGEN-LIMPENS, A. Grounds of Justification (Liability for One's Own Act). In: International Encyclopedia of Comparative Law, vol. XI, Torts (Chief Editor André Tunc), Tübingen/J. C. B. Mohr (Paul Siebeck) - The Hague-Boston-London/Martinus Nijhoff Publishers, 1983, Part 1, Chapt. 2, par. VI., 2-165 - 2-192 (p. 81-93).

MENGONI, L. Irrilevanza dello stato di necessità in tema di responsabilità contrattuale, in (Banca, borsa e tit. di cred., 1951, II, pp. 361-368, nota a Cass. 28 aprile 1951, n. 1032, anche in) ID., Scritti, vol. II, Obbligazioni e negozio, a cura di C. Castronovo, A. Albanese, A. Nicolussi, Milano: Giuffré, 2011. p. 43-52.

MEZZETTI, Enrico. 'Necessitas non habet legem'? Sui confini tra "impossibile" ed "inesigibile" nella struttura dello stato di necessità. Torino: Giappichelli, 2000.

MICHALLEK, Horst-Jürgen. Die Verteilung des wirtschaftlichen Risikos der Nothilfe: Eine rechtsvergleichende Studie. Frankfurt: M., Lang, 1995.

MONATERI, P. G. La responsabilità civile, vol. III de Le fonti delle obbligazioni. In: Trattato di diritto civile diretto da Rodolfo Sacco. Torino: UTET, 1998.

NAVARRETTA, E. Diritti inviolabili e risarcimento del danno. Torino: Giappichelli, 1996.

NATOLI, U. L'attuazione del rapporto obbligatorio: II comportamento del debitore, Milano: Giuffré, 1984. t. II.

NONNE, Luigi. Profili critici dello stato di necessità nel diritto privato. Riv. dir. civ., Milano, v. 63, n. 3, p. 582-607, 2017. 
OSTI, G. Revisione critica della teoria sulla impossibilità della prestazione. Riv. dir. civ., Milano, v. 10, p. 209-259; 313-360; 417-471,1918.

PALLARD, R. L'exception de nécessité en droit civil. Paris: Librairie générale de droit et de jurisprudence, 1950.

PERLINGIERI, Pietro. Dei modi di estinzione delle obbligazioni diversi dall'adempimento: artt. 1230-1259. Delle obbligazioni. In: SCIALOJA, A.; BRANCA, G. (Coord.). Commentario del Codice Civile. BolognaRoma: Zanichelli, 1975. v. IV.

PERLINGIERI, Pietro. La responsabilità civile tra indennizzo e risarcimento. Rass. dir. civ., Napoli, v. I, p. 1061-1087, 2004.

PERLINGIERI, Pietro. II diritto civile nella legalità costituzionale secondo il sistema italocomunitario delle fonti. Napoli: ESI, 2006.

PIRAINO, F. "Ingiustizia del danno" e antigiuridicità. Europa e dir. priv., Milano, a. 2005, n. 3, p. 703-783, 2005.

PIRAS, S. Saggio sul comportamento necessitato nel diritto privato. Sassari: Gallizzi, 1948. (anche in Studi Sassaresi (949, serie II, vol. XII, fasc. III-I., p. 117-201).

PIROVANO, A. Faute civile et faute pénale. Paris: Librairie Générale de Droit Et De Jurisprudence, 1966. spec. §§ 234-255. p. 210-228.

POGLIANI, M. Responsabilità e risarcimento da illecito civile. Milano: Giuffré, 1969.

POLACCO, V. Le obbligazioni nel diritto civile italiano. Roma: Athenaeum, 1915.

RESCIGNO, P. Fortuito, causa non imputabile e diligenza. Banca, borsa e tit. di cred., Milano, 1951, II, p. 388-394, nota a Corte di Appello di Torino, 4 luglio 1951, ivi, p. 388-398.

RESCIGNO, P. voce Obbligazioni (dir. priv.), nozioni generali. In: Enciclopedia del diritto. Milano:

Giuffré, 1979. vol. XXIX. p. 133-211.

RIZZO, N. Giudizi di valore e "giudizio di ingiustizia". Europa e dir. priv., Milano, a. 2015, n. 2, p. 295354, 2015.

RODOTÀ, S. II problema della responsabilità civile. Milano: Giuffré, 1964.

ROSSI, S. voce Necessità (stato di). In: Digesto discipline privatistiche sez. civile. Aggiornamento. Torino: UTET, 2012. p. 704-721.

RUBIN, P. H. Costs and Benefits of a Duty to Rescue. Int. Rev. L. Ec., Amsterdam, v. 6, n. 2, p. 273-276, 1986.

RUBINO, D. Osservazioni in tema di stato di necessità e concorso di persone nel fatto colposo. Riv. giur. circ. e trasp., Milano, cc. 201-210, p. 485-493, 1953.

SÄCKER, F. J. sub § 904, in Münchener Kommentar zum Bürgerlichen Gesetzbuch, Band 6, Sachenrecht, §§ 854-1296, 4. Auflage, München, Verlag C. H. Beck, 2004. p. 636-642.

SACCO, R. L'arricchimento ottenuto mediante fatto ingiusto. Torino: UTET, 1959. p. 190-192.

SAVATIER, R. L'état de nécessité et la responsabilité civile extra-contractuelle. In: AA. VV. Études de droit civil à la mémoire de Henri Capitant. Paris: Librairie Dalloz, 1939. p. 729-752.

SAVATIER, R. Traité de la responsabilité civile en droit français. Les sources de la responsabilité civile. Paris: Librairie générale de droit et de jurisprudence, 1939. t. I.

SCHACK, $\mathrm{H}$. Urheberrechtliche Schranken, übergesetzlicher Notstand und verfassungskonforme Auslegung. In: OHLY, A.; BODEWIG, T.; DREIER, T.; GÖTTING, H.-P.; HAEDICKE, M.; LEHMANN, M. (Hrsg.). Perspektiven des geistigen Eigentums und Wettbewerbsrechts. Festschrift für Gerhard Schricker zum 70. Geburtstag: München, Beck, 2005. p. 511-521.

SCOGNAMIGLIO, R. voce Indennità. In: Novíssimo Digesto Italiano. Torino: UTET, 1962. v. VIII. p. 594-597. 
SCOGNAMIGLIO, R. voce Responsabilità civile. In: Novíssimo Digesto Italiano. Torino: UTET, 1968. v. X. p. 628-657.

SCOGNAMIGLIO, R. voce Responsabilità per fatto altrui. In: Novíssimo Digesto Italiano. Torino: UTET, 1968. v. XV. p. 691-700.

SEILER, H. H. sub § 904, in Staudingers Kommentar zum Bürgerlichen Gesetzbuch, Buch 3, Sachenrecht, §§ 903-924, Sellier. Berlin: De Gruyter, Neubearbeitung, 2002. p. 61-85.

SERIAUX, A. L'œuvre prétorienne in vivo: l'exemple de la convention d'assistance. Mélanges Michel Cabrillac. Paris: Litec Dalloz, 1999. p. 299-311.

STOLL, H. Grounds of Justification as a Defence to Liability - German Law, in AA. VV., In memoriam Jean Limpens. Studiedagen aansprakelijkheidsrecht/Journées d'études sur le droit de la responsabilitél Symposium on Civil Liability. Antwerpen: Kluwer rechtswetenschappen, 1987. p. 207-221.

STOLFI, G. Sull'art. 2045 c.c.. Foro it., Roma, 1951, IV, c. 192.

SUSSMANN, F. B. The Defence of Private Necessity and the Problem of Compensation. Ott. L. Rev., Ottawa, v. 2, n. 184, p. 184-194, 1967.

TABET, A. L'inadempimento contrattuale per stato di necessità. Foro it., Roma, 1951, IV, cc. 193-201.

TITZE, H. Die Unmöglichkeit der Leistung nach deutschem bürgerlichen Recht. Leipzig, Titze, 1900.

TORREGROSSA, G. II problema della responsabilità da atto lecito. Milano: Giuffré, 1964.

TRAVI, A. Indennizzo dovuto dall'incapace. Giur. it., Turim, 1953, I, 1, cc. 497-500, nota a Cass., 28 gennaio 1953, n. 216, ivi, cc. 496-503.

TROISI, B. L'autonomia della fattispecie di cui all'art. 2045 c.c.. Napoli: ESI, 1984.

TROISI, B. Lo stato di necessità nel diritto civile. Napoli: ESI, 1988.

TRÜEB, H. Notwehr und Notstand im allgemeinen und nach schweizerischem Recht. Zürich: Füssli, 1924.

VENCHIARUTTI, A. Lo stato di necessità. In: CENDON, P. (Coord.). La responsabilità civile. Saggi critici e rassegne di giurisprudenza. Milano: Giuffré, 1988, p. 481-495.

VIGANÒ, F. Stato di necessità e conflitti di doveri. Contributo alla teoria delle cause di giustificazione e delle scusanti. Milano: Giuffré, 2000.

VINEY, G.; JOURDAIN, P.; CARVAL, S. Les conditions de la responsabilitè. In: GHESTIN, Jacques (Coord.). Traité de droit civil. Paris: LGDJ lextenso éditions, 2013. p. 663-671. (§§ 566-571).

VIOLANTE, A. Stato di necessità e fatto del terzo. In: Studi in ricordo di Alberto Auricchio. Napoli: Jovene, 1983. p. 1259-1277.

WERNER, O. sub § 228, in Staudingers Kommentar zum Bürgerlichen Gesetzbuch, Erstes Buch, Allgemeiner Teil, §§ 164-240. Berlin, Sellier: De Gruyter, Neubearbeitung, 2001. p. 786-796.

Recebido em: 19/09/2017

Aprovado em: 24/10/2017 